OECDpublishing

\title{
IMPROVING ONLINE DISCLOSURES WITH BEHAVIOURAL INSIGHTS
}

OECD DIGITAL ECONOMY PAPERS

April 2018 No. 269 
This paper was prepared by Anna Barker of the OECD Secretariat. It was approved and declassified by the Committee on Consumer Policy through a written process that concluded on 6 April 2018 and prepared for publication by the OECD Secretariat.

This publication is a contribution to the OECD Going Digital project, which aims to provide policymakers with the tools they need to help their economies and societies prosper in an increasingly digital and data-driven world.

For more information, visit www.oecd.org/going-digital.

\#GoingDigital

Note to Delegations:

This document is also available on OLIS under the reference code:

DSTI/CP(2017)9/FINAL

This document, as well as any data and any map included herein, are without prejudice to the status of or sovereignty over any territory, to the delimitation of international frontiers and boundaries and to the name of any territory, city or area.

The statistical data for Israel are supplied by and under the responsibility of the relevant Israeli authorities. The use of such data by the OECD is without prejudice to the status of the Golan Heights, East Jerusalem and Israeli settlements in the West Bank under the terms of international law.

(c) OECD 2018

You can copy, download or print OECD content for your own use, and you can include excerpts from OECD publications, databases and multimedia products in your own documents, presentations, blogs, websites and teaching materials, provided that suitable acknowledgment of OECD as source and copyright owner is given. All requests for commercial use and translation rights should be submitted to rights@oecd.org. 


\section{Foreword}

This is the latest contribution to work by the OECD's Committee on Consumer Policy $(\mathrm{CCP})$ on improving consumer policy with behavioural insights. Behavioural insights incorporate findings from economics, psychology, neuroscience and marketing to better understand how individuals and businesses actually behave in the marketplace. This report looks at how behavioural insights can be used to improve online information disclosures for consumers.

In particular, many OECD countries have specific information disclosure requirements that businesses have to meet if they are to participate in the market, both online and off. Such requirements address concerns that businesses may otherwise fail to provide sufficient information to allow consumers to make informed decisions. While the role of information disclosure policies is clear, findings from behavioural insights raise questions about the usefulness of certain forms of information disclosure. This report looks at these concerns and the subsequent policy implications. 


\section{Table of Contents}

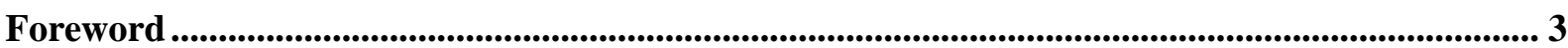

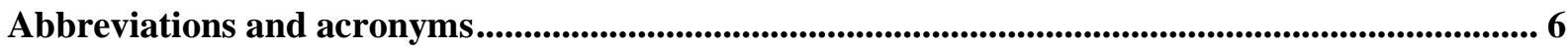

Executive Summary ....................................................................................................................................... 7

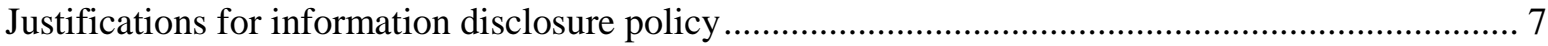

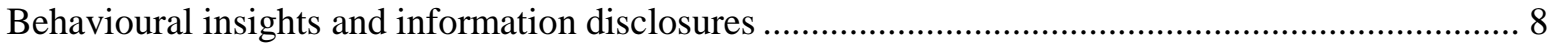

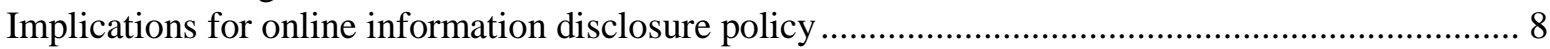

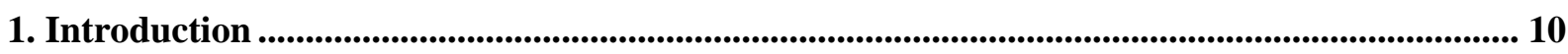

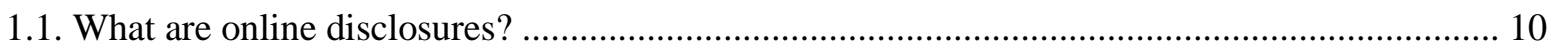

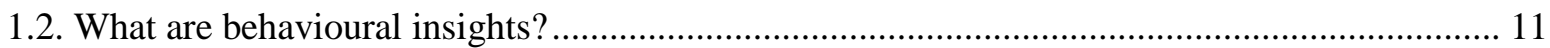

2. Online disclosures and consumer policy.................................................................................................... 14

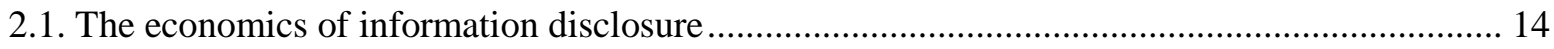

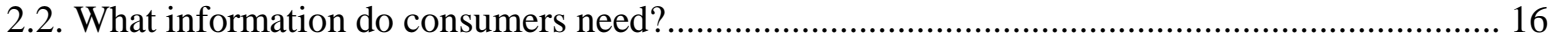

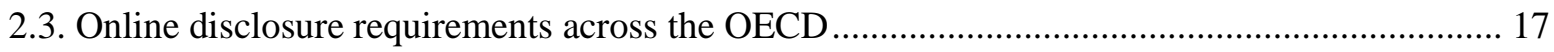

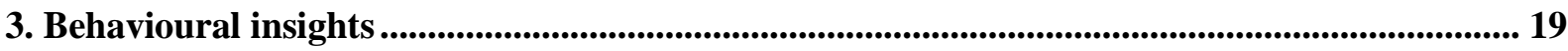

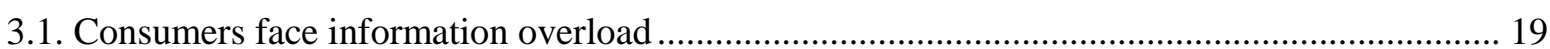

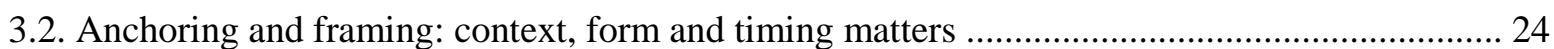

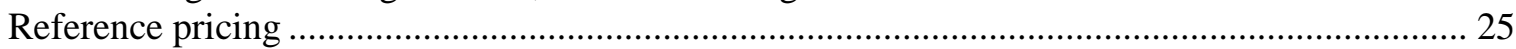

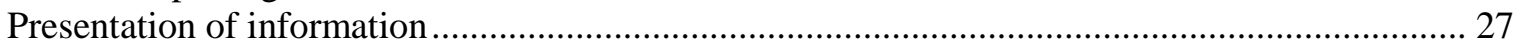

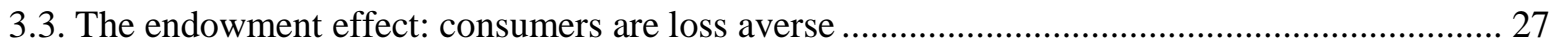

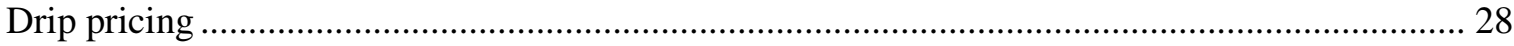

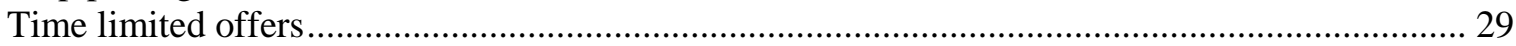

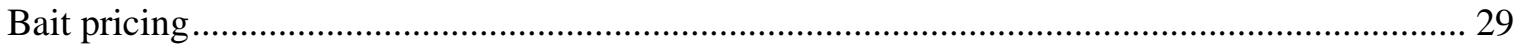

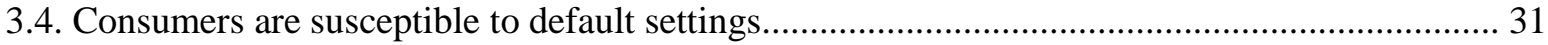

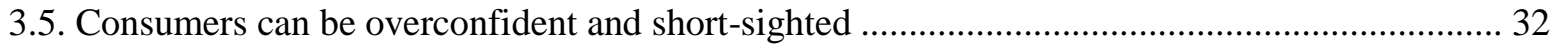

3.6. Social norms and cultural factors can also influence outcomes.............................................. 33

4. Improving online disclosures for consumers............................................................................ 34

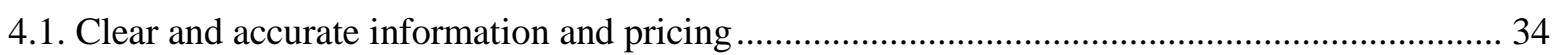

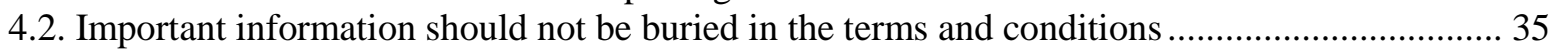

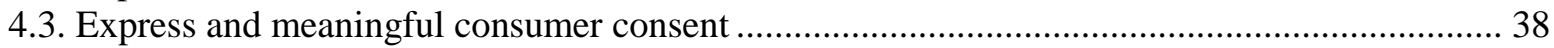

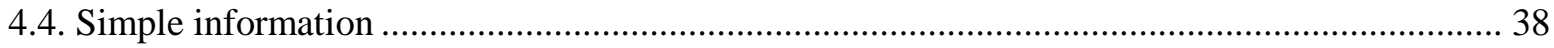

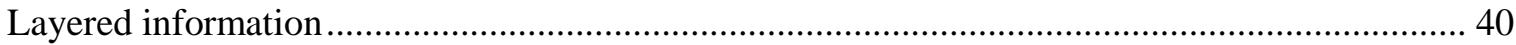

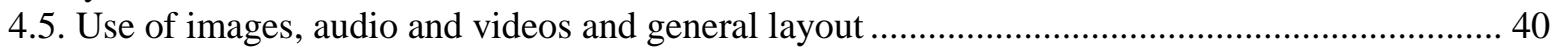

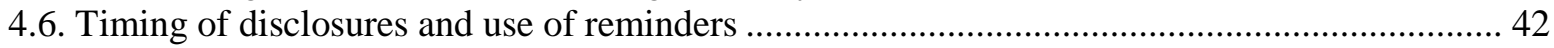

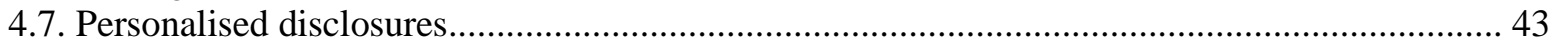

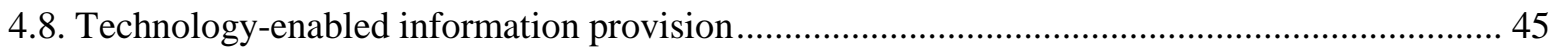

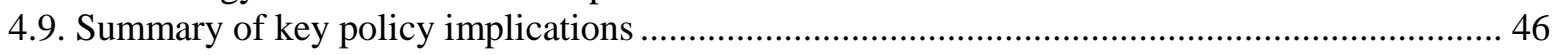

Annex A. Relevant sections of the E-commerce Recommendation......................................................... 48

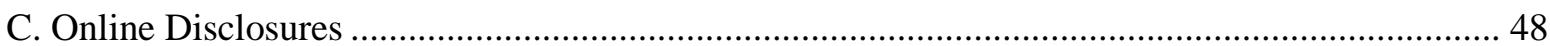

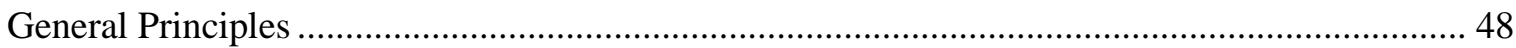

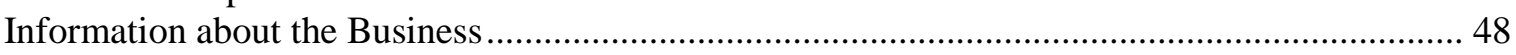




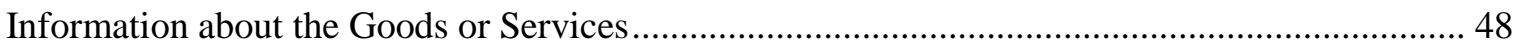

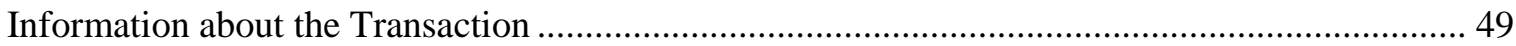

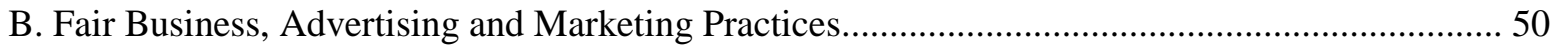

Annex B. Consumer testing ............................................................................................................................ 51

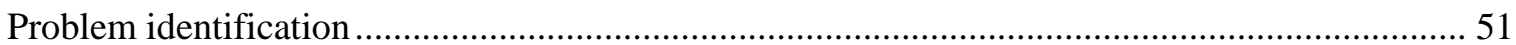

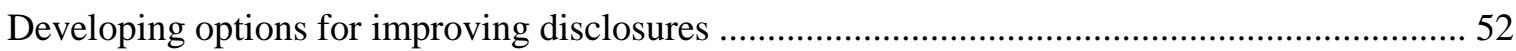

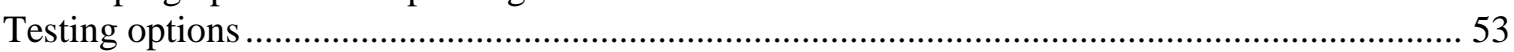

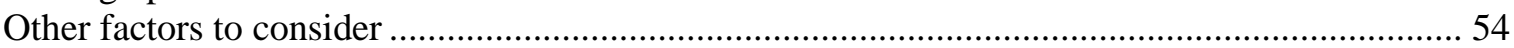

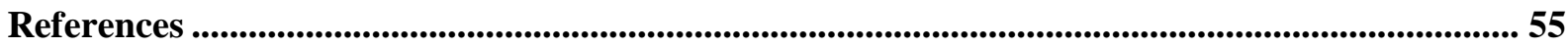

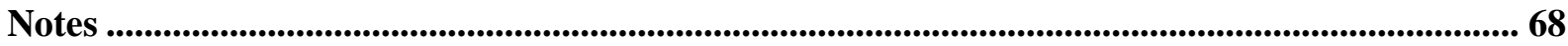

Figures

Figure 3.1. Reading online terms and conditions (T\&Cs) is time consuming .................................... 24

\section{Boxes}

Box 3.1. Examples of behavioural biases related to consumer understanding of online disclosures... 20

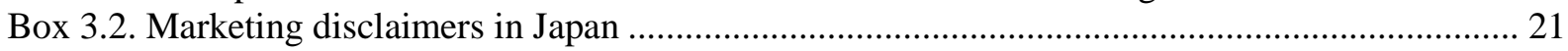

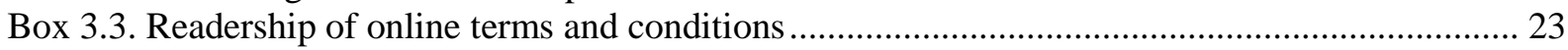

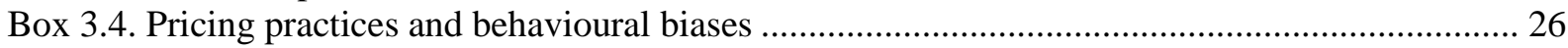

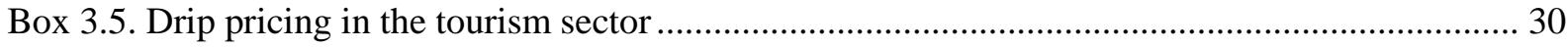

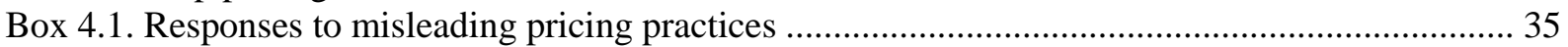

Box 4.2. Using warnings to prevent incompatible digital product purchases online ............................ 41

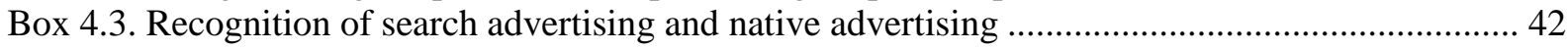

Box 4.4. Annual statements, text alerts, mobile apps and banking behaviour ..................................... 44 


\section{Abbreviations and acronyms}

\begin{tabular}{ll}
\hline ACCC & Australian Competition and Consumer Commission \\
CAA & Consumer Affairs Agency (Japan) \\
CCP & Committee on Consumer Policy (OECD) \\
EC & European Commission \\
CMA & Competition and Markets Authority (United Kingdom) \\
EU & European Union \\
EULA & End User Licence Agreement \\
FCA & Financial Conduct Authority (United Kingdom) \\
FTC & Federal Trade Commission (United States) \\
OECD & Organisation of Economic Cooperation and Development \\
OFT & Office of Fair Trading (United Kingdom) (now the CMA) \\
ROSCA & Restore Online Shoppers' Confidence Act (United States) \\
US & United States \\
\hline
\end{tabular}




\section{Executive Summary}

As anyone who has ever shopped online knows, the Internet is overflowing with information. Access to good information is essential if consumers are to make decisions in their best interests when shopping online. However, is there a point at which consumers have too much information? Further, can the way that information is presented affect consumer decisions? And, if so, how?

This report looks at the historic justifications for online information disclosure in the context of consumer policy, and then reassesses this through a behavioural lens. It draws together the current literature and makes a number of high level recommendations for improving online information disclosures to ensure empowered consumers online. It builds on over a decade of work by the Committee on Consumer Policy (CCP) on incorporating behavioural insights into consumer policy to achieve better outcomes for consumers.

\section{Justifications for information disclosure policy}

Consumers use a wide variety of information in their decision making, including information obtained from the observation and use of products, and information from third parties including friends and family, businesses (via advertising and marketing), governments, intermediaries and independent organisations. This is true for both online and offline purchases. Increasingly, however, consumers are obtaining more and more information from online sources, like digital ads, blogs, social media, ratings and comparison websites, as well as "paid" or "sponsored" online content that may bear a similarity to news, feature articles and product reviews, for example.

While online disclosures may be relatively new, economists have long focused on the role of information in correcting market failures that harm consumers. In particular, information economics recognised that, if left to the market, consumers may not always have enough, or the right type, of information to make informed decisions. This is especially relevant where there are "information asymmetries" (i.e. when sellers know more about the features and quality of their products or services than consumers). Further, the economics of information literature recognised that there are costs involved for businesses in providing information, and for consumers in searching for and understanding information. It therefore posited that disclosures that make product pricing and features more transparent could reduce search costs, potentially improving outcomes for consumers. For these reasons, most OECD countries have legislation or guidelines that ensure that consumers have access to clear, accurate, and easily accessible information when shopping online (and off).

While information economics, with its focus on information disclosure, underlies much of consumer policy, it does not completely explain how consumers actually understand and use information. Indeed, while information economists have long recognised limits in consumer understanding and information processing, the behavioural insights literature has shown that "acquiring and assessing information may be more troublesome for consumers than information economics assumes" (Faure and Luth, 2011, p. 346 $6_{[1]}$ ). Accordingly, in recent years policymakers have started to focus more attention on how 
consumers process information, and the impact of form and context on consumer decision making, using tools and techniques from behavioural insights.

\section{Behavioural insights and information disclosures}

Behavioural insights incorporates findings from economics (drawing on the related field of behavioural economics), psychology, neuroscience and marketing to better understand consumer behaviour and decision making. Behavioural studies have shown that consumers can be subject to behavioural biases that might limit the effectiveness of some forms of online disclosures. Further, behavioural insights can highlight why some of the disclosure tactics that are employed by certain businesses can be effective in eliciting consumer behaviour that is not always in a consumer's best interest.

One of the key findings from behavioural insights is that consumers face information overload: there is only so much information they can take into account. This is especially true for decisions concerning complex products and/or a large array of choices. If faced with more information than they can process, consumers can disengage, resulting in suboptimal outcomes either because they ignore certain choices, make a decision based on a limited range of information, or defer a decision. One consequence of information overload is that few consumers read online terms and conditions in full, or at all.

Further, numerous behavioural studies have found that presenting one choice to consumers as a default can induce consumers to choose that option. Hence, certain practices that prey on default biases, such as pre-checked boxes and negative option marketing, can be used by businesses to distort consumer decision making. Similarly, default biases can be used by policymakers to try and engender certain behaviour by consumers (or citizens) in the pursuit of specific policy objectives.

How a choice or disclosure is presented to consumers can have a significant impact on consumer decision making. Consumers may be susceptible to anchoring and framing effects. For example, many consumers perceive the value of two identically priced offers to be different if one is presented next to a higher "pre-sale" price. Many consumers are also loss averse, which means that if an offer is presented as preventing a loss it may elicit a greater response than if presented neutrally. For example, time limited offers may prime consumers with a perceived loss if they miss the offer. Drip pricing and bait pricing also prey on this behavioural bias.

In addition, consumers can be overoptimistic about potential benefits and short-sighted about future risks or costs, which can further hinder their ability to make decisions in their best interests. This may lead consumers to misjudge their future needs, ignore or discount warnings, or otherwise fail to take due consideration of relevant information. Social and cultural norms are also important and can influence how consumers interact with online disclosures.

\section{Implications for online information disclosure policy}

The abovementioned behavioural biases can potentially limit the effectiveness of online information disclosures. The implications for online information disclosure policy are discussed below.

Consumers can only process so much information and will do so selectively depending upon context; and in some circumstances will not absorb any information. For this reason, it is important that online disclosures (including pricing information) are made as simple, 
clear, accurate and relevant as possible. One important policy implication of this is that governments should ensure that mandated disclosure requirements do not introduce more complexity or volume than is absolutely necessary.

Further, terms and conditions are not the (only) place for businesses to convey important information to consumers given that few consumers read these in full or at all. Instead, businesses should ensure that key information is displayed prominently and saliently, potentially in multiple places on a business' website and at various times in the transaction process. Further, governments should continue to ensure that consumers are protected against unfair terms and conditions in online standard form contracts. In addition, given consumers tend to follow default settings, businesses should ensure that any consumer consent is obtained in an express and meaningful way.

In designing online disclosures, businesses (and policymakers who are considering mandated requirements) should be mindful of the impact of form and context. In addition, use of images, audio and video should be considered. The timing of disclosures also matters and should be considered in understanding how best to communicate with consumers.

One way to improve the simplicity of disclosures would be to make these more personalised. This could improve disclosures by removing irrelevant information, highlighting pertinent information and could even pick up personal preferences about what, where and when to disclose. However, personalisation has the potential to raise new consumer issues and requires further research.

While consumers struggle with too much information, more complex information can potentially be used by algorithm-based technologies to assist consumer decision making. Policymakers and businesses should be aware of this alternative use of information.

Moreover, governments should ensure that any mandated requirements do not impede businesses' ability to innovate to develop more effective online disclosures for consumers. In considering changes to online disclosure requirements policymakers should conduct empirical research to determine how consumers actually interact with disclosures, including by testing the actual effects of alternative disclosure designs.

In summary, to ensure that online disclosures are effective for consumers, the behavioural insights literature suggests that:

- information and pricing should be simple, clear, accurate and relevant

- businesses should not rely on terms and conditions to convey important information

- businesses should obtain express and meaningful consumer consent

- images, audio and video should be used where appropriate; not just text

- when consumers receive information is of key importance

- personalisation could potentially be used to improve disclosures

- more complex information should be presented in a way that enables analysis by technology-enables third parties

- consumer testing of information disclosures is important and should be undertaken whenever new disclosure requirements are being considered. 


\section{Introduction}

The OECD's CCP has been analysing consumer policy using behavioural insights for over a decade as part of its work on effective consumer policy making. ${ }^{1}$ Behavioural insights incorporate findings from economics, psychology, neuroscience and marketing, to allow policymakers to better understand how individuals and businesses actually behave in the marketplace. Specifically, behavioural insights can be used to identify, test and measure behavioural biases to improve policy design. In the last decade, policymakers have substantially increased the use of behavioural insights in the design and delivery of consumer policy (OECD, 2017 $[2]$ ).

Information disclosure is a key tool for consumer policy. Many OECD countries require businesses to disclose certain types of information, often in specified ways, to enable consumers to make informed decisions by addressing issues of asymmetric information. In particular, while effective competition may encourage businesses to provide some information to consumers, in the absence of broader disclosure requirements, businesses might only disclose information that improves their chances of making a sale. Hence, if left to the market there might be issues of adverse selection - that is, businesses might not disclose information about the risks and limitations of the products and services they are selling. Further, businesses might be tempted to bend the truth in order to increase sales.

While information disclosure is likely to remain a key tool for empowering consumers, findings from behavioural insights suggest that a rethink is required about the usefulness of certain forms of information disclosure. In particular, consumers experience difficultly in processing large amounts of information, are influenced by the way information is presented, and rarely read information contained in contractual terms and conditions.

The purpose of this report is to look at online information disclosures through the behavioural lens with a view to improving online disclosures and empowering consumers. Examples are drawn from online and offline experiences but the policy implications are focussed on the online environment given the growing importance of this to consumers across the OECD.

\subsection{What are online disclosures?}

Online disclosures can provide consumers with information about the seller, the goods and services on offer, and the transaction itself, including information about payment methods, privacy policies and available dispute resolution and redress options (OECD, $\left.2016_{[3]}\right)$. Businesses may make such disclosures through advertising and marketing (ranging from display banners to embedded "native advertising" in online blogs, social media sites and news sites), contractual terms and conditions, and legally-required notices. This information can be conveyed in different ways, including through pop-ups, links, text, images, audio and video. Businesses can provide this information at different points throughout a transaction process including through pre-transaction advertising and marketing and during the course of the transaction, often through the confirmation and payment process.

Information disclosures are just one of a number of available tools for addressing consumer policy issues $\left(\mathrm{OECD}, 2010_{[4]}\right)$. In the online context, disclosures may be an important way of communicating with consumers that might not be able to interact with 
products in the same way that they would in "bricks and mortar" stores. For example, consumers may not be able to touch and feel physical products when shopping online. However, consumers may be able to sample digital products in a way that they cannot with physical products. Similarly, interactions with customer service staff in bricks and mortar stores may be replaced by online assistants or "chat" services. In addition, the Internet lends itself to new ways of interacting with consumers which means that the online disclosures may be fundamentally different from their offline counterparts (in terms of how, when and where information is conveyed, for example) even if they include the same substantive information.

Further, what works for a recipient of a print disclosure may not work when transferred to another recipient's "screen of choice", be it a computer monitor, tablet or a mobile device (Benartzi and Lehrer, 2017 $[5]$. ${ }^{2}$ Different delivery channels for consumer disclosures may require businesses to revise both the format and content of information. Further, the multi-dimensional nature of the Internet can often enable consumers to easily find more detailed information as required, allowing consumers to become better informed about a particular product or service. However, while information is prevalent on the Internet, consumer attention remains a scarce resource and some sources of information are more effective than others. In this context, getting consumers to notice and then click on key links can be as challenging as getting them to interact with traditional paper disclosures (Hogarth and Merry, 2011 $1_{[6]}$ ), perhaps even more so (Benartzi and Lehrer, 2017 ${ }_{[5]}$ ).

"Internet of Things" products are likely to raise their own unique issues for information disclosure. For example, disclosure may be more of an issue across the life of the product rather than just at the pre-purchase stage. Further, businesses will have to consider how to effectively communicate with consumers in instances where a lack of a physical screen may make it difficult to communicate in traditional ways with text or images. Digital content products also raise their own unique set of issues. ${ }^{3}$

\subsection{What are behavioural insights?}

The multi-disciplinary study of behavioural insights and its application to public policy is relatively new, although it has been researched and applied for some time in specific policy areas or parts of the world to achieve certain goals, for example, automatic enrolment in retirement plans (Lunn, 2014 $[7]$; Naru and Cavassini, 2017 $[8]$ ). Behavioural insights is gaining acceptance and momentum as an effective tool for improving public policy across a number of sectors and policy areas, as evidenced by the OECD's (2017 $\left.{ }_{[9]}\right)$ report which collects over 100 case studies on applying behavioural insights to public policy around the world. It is estimated that over 150 governments make use of behavioural insights to influence consumer behavior and consumer choices (Sunstein, Reisch and Rauber, 2017 $[10]$ ) and there are at least 130 behavioural initiatives institutionalised in or with public bodies involved with public policy (Naru and Cavassini, $\left.2018_{[11]}\right)$.

Behavioural insights are (OECD, 2016, p. 22 $\left.2_{[12]}\right)$ :

... grounded in a multi-disciplinary approach where traditional economic strategies are mixed with insights from behavioural economics, cognitive- and social-psychology and, to some extent, cognitive design to create policies that take into account the many 'irrational' factors that influence consumers decision making ... 
Behavioural insights are underpinned by the use of experiments and empirical analysis. It builds on an inductive approach to policy making that researches issues and problems related to the actual rather than the assumed behaviour of individuals and tests possible solutions before designing policy interventions (see also Annex B). As noted by the $\operatorname{OECD}\left(2017\right.$, p. $\left.16_{[9]}\right)$ :

Behavioural insights aim at improving the welfare of citizens and consumers through policies and regulations that are formed based on empirically-tested results, derived using sound experimental methods.

"Behavioural economics" can be viewed as a sub-category of behavioural insights that incorporates psychological insights into the study of economic problems (OECD, $\left.2017_{[2]}\right)$. Throughout this report, the term "behavioural insights" is used to reflect its multi-disciplinary nature.

Traditionally, consumer policy has been informed by economic theory, though some consumer policies also take into account social and moral objectives. Under economic theory, market interventions have tended to be justified on the basis of market failure (for example, imperfect or asymmetric information). While economic theory remains the starting point for investigating consumer policy (see Section 2.1), behavioural insights can help to test certain economic assumptions about consumer (and business) behaviour, and to adapt policy design and delivery where appropriate (OECD, 2017 $\left.7_{[2]}\right)$.

While many of the biases that have been uncovered by behavioural insights may be relevant to consumer issues broadly, this does not necessarily imply that wholesale changes to consumer policy are warranted. Instead, behavioural insights should be considered in the context of the specific policy question under investigation. In particular, findings from behavioural experiments cannot necessarily be generalised beyond the specific policy question that an experiment was designed to address.

A further issue in using behavioural insights to improve online disclosures is that the overarching aim is to empower consumers to make decisions that are in their best interests (whatever those may be). That is, the goal is to preserve consumer autonomy by giving consumers the necessary information to make the best decisions possible in the circumstances. This differs from many other areas in which behavioural insights have been applied in that policymakers (or indeed businesses) usually have a clear behaviour that they want to invoke in consumers or citizens (albeit while potentially retaining the consumer's/citizen's ability to make a different decision). Such interventions are commonly referred to as "nudges" (Thaler and Sunstein, $\left.2008_{[13]}\right)$. Some examples from the literature include policy interventions that aim to increase tax compliance (Hernandez et al., 2017 $[14]$ ), reduce energy use (Allcott, 2011 ${ }_{[15]}$ ), increase organ donation (Johnson and Goldstein, 2004 ${ }_{[16]}$ ), reduce litter (Kolodko, Read and Taj, 2016 ${ }_{[17]}$ ) and promote healthy eating (Shahnazari et al., 2016 $\left.{ }_{[18]}\right)$. It is likely that policy interventions can be more tailored in these scenarios than for a high-level goal such as improving online disclosures. Notwithstanding this, the behavioural literature does provide some useful insights for how to best use and design online information disclosures in a general sense. Further, for specific issues relating to online disclosures there may be more scope to develop targeted policy interventions (though these may not be able to be applied at a wholesale level). In this respect, consumer testing of policies relating to online disclosure is particularly important (see Annex B).

This report aims to look at how lessons from behavioural insights can be used to develop more effective online disclosures both in a general way and in specific policy settings. 
First, Chapter 2 looks at the economic and other justifications for information disclosure policies, and existing requirements across the OECD. Next, Chapter 3 looks at learnings from behavioural insights. Last, Chapter 4 discusses suggestions for improving online disclosures for consumers. Annex A reproduces relevant sections of the OECD's "Recommendation on Consumer Protection in E-commerce" (hereafter "the E-commerce Recommendation"). Additional information on how to undertake consumer testing of information disclosures is contained in Annex B. 


\section{Online disclosures and consumer policy}

Clear and effective online information disclosure is fundamental to ensuring that consumers can fully engage in the digital economy. In particular, if consumers do not have the right amount and type of information, this may hinder their ability to make decisions that are in their best interests when shopping online. Further, well informed consumers are important to ensuring effective competition between businesses online. As noted by Beales et al. (1981, p. 492 [19]):

Information about price, quality, and attributes allows buyers to make the best use of their budget by finding the product whose mix of price and quality they most prefer. In turn, buyers' ability to locate preferred products gives sellers an incentive to compete to improve their offerings by allowing buyers to find and reward (with patronage) the seller whose offer they prefer. Without such information, the incentive to compete on price and quality will be weakened, and consumer welfare will be reduced.

In this way, "confident, informed consumers who make well-reasoned decisions represent powerful drivers of innovation, productivity and competition" (OECD, 2010, p. 28 $8_{[4]}$ ). This section discusses the economics of information disclosure, what information consumers need, and provides examples of online information disclosure requirements across the OECD.

\subsection{The economics of information disclosure}

As noted in the OECD's Consumer Policy Toolkit, economic theory suggests that free markets generally provide the best outcomes for consumers (OECD, 2010 $\left.0_{[4]}\right)$. However, this is based on a number of assumptions. Namely, that: markets are perfectly competitive; there are no market failures; market players act in their best interests; there are no externalities; and there is perfect and complete information. If these assumptions do not hold, free markets might not provide the best outcomes for consumers and there may be a case for considering policy intervention.

The assumption that market participants (and particularly, consumers) have access to full and complete information rarely holds in practice. In particular, consumers rarely know all the attributes of products and services in the market. "Information economics" or "the economics of information" emerged in the 1960 and 1970s to better understand the impact of imperfect information (Stigler, 1961 [20]). Information economics highlighted that there are costs involved in providing and obtaining information (Stiglitz, 2000 21$]$ ). Hence, businesses and consumers undertake a cost-benefit assessment in deciding what information to provide to, or seek out in, the market.

Information economics also recognises that asymmetric information can be a problem, especially if the attributes and qualities of a good or service cannot be ascertained before a purchase is made. As compared to search goods or services, whose attributes can be easily evaluated before purchase, attributes of:

- experience goods or services can only be determined by a consumer after purchase and use (for example, a restaurant meal). 
- credence goods or services cannot be determined even after purchase and use (for example, preventative medicine) (Nelson, 1970 [22]; Nelson, 1974[23]; Darby et al., $\left.1973_{[24]}\right)$.

Hence, for experience and credence goods and services, the seller can provide information to consumers but consumers may be unable to verify this information before making a purchase. This can lead to an "adverse selection" or "lemons" problem where higher quality goods are driven out of the market (Akerlof, 1970 ${ }_{[25]}$ ). This happens because sellers of high quality goods cannot convince consumers of the quality of their goods and so cannot elicit a higher price for the higher quality. If businesses cannot obtain a higher price for higher quality goods (and assuming they cost more to produce) businesses will stop supplying them and the quality of goods offered in the market will fall.

Businesses might also undersupply information if they cannot retain the full benefit of doing so for themselves (Beales, Craswell and Salop, 1981 ${ }_{[19]}$ ). Information about the generic benefits of a type of product falls into this category. For example, if a banana producer advertises the health benefits of bananas, banana sales may increase but not necessarily the sales of that particular banana producer: the producer's competitors would "free-ride" on the investment. Hence, the producer may have little incentive to produce this type of information.

Consumers may also undertake less searching than is privately optimal since they can free ride on the search activities of others (Salop and Stiglitz, 1977 ${ }_{[26]}$ ). Specifically, consumers might get recommendations from friends and family which leads them to reduce their search activities (Deltas and Li, 2017 $[27]$ ). Informed consumers are also more likely to take actions to discipline market players which can have broader benefits for all consumers in the market (Beales, Craswell and Salop, 1981 $\left.{ }_{[19]}\right)$. Overall, this means consumers will undertake less search activity than they would if they could not benefit from the search activities of others.

Asymmetric information is likely to be a particular problem in markets that are not sufficiently competitive. In addition, companies with market power may actually provide too much information in an attempt to overwhelm consumers so that they stick with the status quo (Beales, Craswell and Salop, 1981 $\left.{ }_{[19]}\right)$.

For some of the issues identified above, there may be scope for market-based solutions. For example:

- Producers of high quality products have an incentive to convince consumers of the quality of their products so as to attract a higher price. For example, businesses can enhance their credibility by offering warranties, certification, guarantees or refunds (Dewally and Ederington, 2006 288 ; Productivity Commission, 2008 ${ }_{[29]}$; Rischkowsky and Döring, 2008 $\left.{ }_{[30]}\right)$.

- Businesses (especially those that rely on repeat customers) have incentives to invest in building their brand and reputation (Beales, Craswell and Salop, 1981 [19]; Productivity Commission, 2008 ${ }_{[29]}$ ). In this respect, online businesses may use online ratings and reviews to try to improve their reputation and build consumer trust (Bei, Chen and Widdows, 2004[31]).

- Regarding concerns about free-riding by competing producers, this could be addressed through industry-wide advertising and marketing campaigns (so long as they do not raise competition issues) (Beales, Craswell and Salop, 1981 [19]). 
- Consumers may be able to verify the quality of a good or service by using third-party information such as that provided by brokers, consumer associations, intermediaries and other online platforms (OECD, 2010[4]). Such information is widely available online for a variety of goods and services (see, e.g., Section 4.8). Of course, using these services involves additional search costs and these services may raise other consumer protection issues. Further, online ratings and reviews may have their own limitations (Aral, 2013 ${ }_{[32]}$ ).

In this context, government intervention should only be considered when market mechanisms fail to address the market failure or create new consumer protection concerns.

Nonetheless, some issues discussed above are unlikely to be solved through market solutions. In particular, businesses might still face incentives to publish false or misleading information, or may not publish sufficient information. This may lead consumers to make decisions that are not in their best interests (OECD, 2005 [33] ). In addition, these practices may distort competition and undermine consumer trust (Beales, Craswell and Salop, 1981 $1_{[19]}$ ).

False or misleading claims are most likely to be a concern for credence goods or one-off experience goods. This is because consumers may not have sufficient information to verify claims in these circumstances. Even in the Internet age where there is a wealth of information available, consumers may still face difficulties in verifying the claims made by businesses in respect of certain types of goods and services (Dimoka, Hong and Pavlou, 2012[34]). Further, competing businesses may not counter the claims if they have the same failings or the benefits of doing so do not outweigh the costs. For example, no cigarette company is likely to highlight the health problems associated with smoking. In addition, a business might not counter a competitor's claims if it is costly to do so and/or they will not gain new consumers as a result. For these reasons, many countries have laws that prohibit businesses from making false or misleading claims (including by omission).

Issues of insufficient information provision by businesses have tended to be addressed through mandated disclosure requirements. Information disclosures have a number of benefits. One is that they do not interfere with free trade in that they rarely restrict the types of products or services that businesses provide and leave consumers free to make choices regarding those products or services (Howells, 2005 ${ }_{[35]}$ ). In addition, information disclosures tend to maintain personal autonomy (Grundmann, Kerber and Weatherill, $\left.2001_{[36]}\right)$. However, as will be discussed in the following chapters, designing effective disclosures that empower consumers is not straightforward.

\subsection{What information do consumers need?}

The information that consumers require in order to make informed decisions when shopping online is one of the questions that the CCP considered in revising the E-commerce Recommendation. Section $\mathrm{C}$ of the E-commerce Recommendation addresses online disclosures and provides general principles and more specific details about the types of information that online businesses should make available to consumers. This and other relevant parts of the E-commerce Recommendation are reproduced in Annex A.

In relation to the content of online disclosures, the E-commerce Recommendation recommends that online businesses provide consumers with information about themselves, the goods or services for sale, and the transaction. The overarching goal is 
that consumers have sufficient information to make an informed decision regarding a transaction. The key elements of informed decision making relate to knowing the price and attributes of the product or service, the terms and conditions of sale, payment and delivery, and parties' rights after purchase.

While the E-commerce Recommendation is relatively detailed in the types of information that businesses should provide to consumers, it does not prescribe how and when this information should be provided except to say that online disclosures should be:

- clear, accurate, easily accessible and conspicuous

- made in clear and easy-to-understand language in the relevant local language and local currency

- made at a relevant time

- provided in a way that enables consumers to retain a complete, accurate and durable record

- cognisant of the device or platform over which the transaction occurs.

Some of these requirements inherently pick up on findings from behavioural insights. They recognise that consumers are not only influenced by the content of information but also by how and when information is presented. This is discussed in more detail in Chapter 3.

In practice, businesses may provide much of the information detailed in the E-commerce Recommendation without being required to do so. Many of these represent common sense information that any business wanting to establish a loyal following of consumers would want to make available. However, other information might not be provided so willingly - for example, businesses whose products or services lack interoperability might not be so inclined to disclose this information.

\subsection{Online disclosure requirements across the OECD}

Online disclosure requirements differ across the OECD; this section provides a very broad overview of some of the main approaches.

At a general level, most OECD countries have legislation that prohibits businesses from misleading or deceiving consumers. These laws usually apply equally whether a consumer is making a purchase on or offline. In this way, the laws in OECD countries protect consumers from making purchases based on false or misleading information. Some specific types of misleading or deceptive practices are also prohibited or restricted in a number of jurisdictions. These are discussed as relevant throughout the remainder of the report. Such prohibitions and restrictions address some of the information asymmetries that exist between businesses and consumers (including in relation to adverse selection) and recognise the importance of accurate information to effective competition and well-functioning markets.

In addition, a number of jurisdictions (for example, Canada, Costa Rica, the European Union (EU), Japan and the United States) have additional requirements to ensure that advertising material does not mislead consumers. In some cases these requirements are complemented with guidance material. For example, in 2016 the US Federal Trade Commission released an "Enforcement Policy Statement on Deceptively Formatted Advertisements" that lays out the general principles the agency considers in determining whether any particular ad format is deceptive and applies them to modern media. 
Some OECD countries also have mandated "lists" of information that businesses are required to provide to consumers. The specificity of these lists varies by jurisdiction.

In the EU, for example, online businesses are required to provide twenty types of information to consumers under Article 6 of the Consumer Rights Directive $\left(2011_{[37]}\right)$. These include details about the good/service, the trader, price information, consumer rights and guarantees, payment and delivery details, contract details, interoperability of digital content, and consumer redress.

In Canada, eight Provinces have adopted the Internet Sales Contract Harmonization Template which lists thirteen types of information that online businesses have to provide to consumers. These requirements were developed to be consistent with the OECD's 1999 Guidelines for Consumer Protection in the Context of Electronic Commerce ([38]) (which is largely consistent with the updated E-commerce Recommendation). Similar requirements exist in Costa Rica where businesses are required to provide various types of information to consumers, consistent with the requirements outlined in the 2016 E-commerce Recommendation.

Israel has a smaller list of seven pieces of information that online businesses have to provide to consumers at the marketing stage (s.14C, Consumer Protection Law 1981). In addition, it requires businesses to highlight any defect or known characteristic that significantly diminishes the value of a good, and any required maintenance or method of use in order to avoid injury during the ordinary use or handling of that good (s.4, Consumer Protection Law 1981).

In Mexico businesses are only required to provide their address and telephone number. However, Mexican law also provides consumers with the right to know all the information about the terms, conditions, costs, additional charges, if any, and payment forms for the goods and services offered by businesses (see Article 76 BIS, Chapter VIII BIS, Consumer Protection Law).

In the US, there is no list of information that all businesses are required to provide to consumers under federal law. Instead, the Federal Trade Commission (FTC) Act prohibits businesses from engaging in unfair or deceptive acts. The practical implications of this for what businesses should disclose online has been developed through case law and FTC guidance including rules, enforcement policy statements, formal guidelines, and informal staff guidance. In addition, there are a number of state-based laws and rules that require particular businesses to provide certain types of information to consumers. For example, the California Civil Code $\$ 1789.3$ requires e-commerce providers to inform consumers of the name, address, and telephone number of the provider, consumer charges, and dispute resolution.

In other jurisdictions businesses are encouraged (rather than required) to provide similar types of information. For example, the Australian Government's (2006 [39]) "Guidelines for Electronic Commerce" recommends that online businesses provide various types of information to consumers, largely consistent with the information listed in the Ecommerce Recommendation (OECD, 2016 $\left.6_{[3]}\right)$.

In addition, many OECD countries have additional information disclosure requirements that apply to specific markets and sectors including in the online context. For example, there are detailed disclosure requirements for certain consumer disclosures in telecommunications, regulated utility and financial services in a number of OECD countries. 


\section{Behavioural insights}

This section looks at the literature on consumer behaviour regarding information disclosures and identifies key lessons. In particular, the behavioural insights literature suggests that there are a number of behavioural "biases" that may hinder the effectiveness of online information disclosures, including information overload, the endowment effect, default and status quo effects, anchoring, framing, overconfidence and time inconsistency/myopia (see Box 3.1). These are discussed below.

\subsection{Consumers face information overload}

There are limits to the amount of information that consumers can process (Miller, $\left.1956_{[40]}\right)$. Information overload occurs when consumers are confronted with complex products or a large range of choices and find it difficult to engage with the decision. Ultimately, consumers may choose not to make a decision, or may base their decision on relatively simple "rules of thumb" or "heuristics" (OECD, 2017 $[2])$.

This can potentially lead to consumer harm if consumers put off making a purchase that would have made them better off, or make a wrong decision (for example, staying with their existing supplier when they would be better off switching). Indeed, Levav et al. $\left(2010_{[41]}\right)$ found that when confronted with an increasing number of options, consumers were more likely to stick with the default option. Further, numerous studies have found that "when people are overloaded, they feel less satisfied, less confident, and more confused" (Lee and Lee, 2004, p. 177 $\left.7_{[42]}\right)$.

Consumers use a variety of information when making purchasing decisions, including (OECD, 2010, p. 34 $\left.{ }_{[4]}\right)$ :

Information obtained from observation and use of the product, from friends and family, from firms via advertising and other marketing activities, and from third parties such as the government, intermediaries and independent organisations.

In the digital economy there is even more, and more varied types and sources of, information available to consumers. As noted in a report by the United Kingdom's former Office of Fair Trading (OFT) (2007, p. 26 $\left.6_{[43]}\right)$ :

The internet provides consumers with a wealth of information from relatively accessible price information, to specialist forums where people can discuss products, suppliers and deals. Search engines and price comparison sites are potentially valuable facilitators of information which, if used effectively, can enable people to compare many products and prices and select the best deal for them - possibly at lower prices than they could otherwise find.

However, the OFT $\left(2007_{[43]}\right)$ also found that consumers are frustrated by the mass of poorly structured information available online as this can cause information overload and increase search times. Rather than facing a problem of insufficient choice, consumer can instead feel constrained by their inability to compare offers due to an excess of information and options (Gill Wales Research, 2014[44]). Indeed, a study commissioned by the European Commission (EC) found that when shopping online (as compared to 
offline), consumers are more "motivated to avoid information overload and simplify choice" (Leenheer et al., 2014 $\left.{ }_{[45]}\right)$. Benartzi and Lehrer $\left(2017_{[5]}\right)$ had similar findings.

\section{Box 3.1. Examples of behavioural biases related to consumer understanding of online disclosures}

Information overload: When faced with complex products or a bewildering array of choices, consumers may ignore possible choices or choose not to choose. Consumers may also rely on simple "rules of thumb" or "heuristics".

Default and status quo effect: Presenting one choice as a default option can induce consumers to choose that option. The power of default is related to the status quo effect, where consumers have a strong tendency to remain at the statusquo.

Endowment effect: Consumers often demand much more to give up an object than they would be willing to pay to acquire it: consumers value a good more highly when it becomes a part of their endowment. This is because consumers tend to be loss averse.

Anchoring: Consumers "anchor" decisions around the information that they think is the most important. This means consumers may fail to adjust their perception of the value of the offer sufficiently, even when additional information is provided.

Framing: Consumers are influenced by how information is presented. Presenting an option in a certain way may induce consumers to evaluate the choice from a particular reference point.

Priming effect: When consumers are repeatedly exposed to something, for example, through publicity, certain attributes can play an undue role in consumer decisions. Priming can influence preferences by making certain attributes salient.

Overconfidence: Consumers tend to think that they are more likely to experience an outcome from some action that is better than the average expected outcome. For example, most drivers think that they are safer than the average driver.

Hyperbolic discounting and myopia: Consumers tend to treat the present as if it were much more important than future time periods. This explains outcomes such as low retirement savings in the absence of compulsion.

Time-inconsistency: Consumers may make choices that are not consistent across time periods due to conflicts between short-term urges and long-term interests.

Social and cultural norms: Consumers are often guided by the values, actions, and expectations of a particular society or group. For example, when people are made aware of what others are doing, it can reinforce individuals' underlying motivations.

Source: adapted from OECD (2017, p. 9[2]).

So it seems that greater information provision does not necessarily translate into better outcomes for consumers. As noted by Citizens Advice (2016, p. 28 $\left.8_{[46]}\right)$ : "despite more information on the purchase being made available to consumers, most do not read it 
thoroughly and many don't understand it properly". A study undertaken by Japan's Consumer Affairs Agency on marketing disclaimers illustrates this issue (see Box 3.2).

\section{Box 3.2. Marketing disclaimers in Japan}

Japan's CAA undertook a study to understand consumer attitudes towards, and the effectiveness of, marketing disclaimers (which it calls "reservation representations") in relation to "emphasised claims". The study's findings suggest that few consumers notice such disclaimers and even when they do, many do not read them. The study was based on a consumer survey and consumer experiments involving various forms of disclaimers.

The survey first asked whether consumers usually pay attention to disclaimers in various forms of media. For online marketing, over $57 \%$ of survey respondents chose not to read disclaimers even when they were on the same page of a computer screen. This increased to over $75 \%$ when the consumer had to scroll down on their smartphone. The main reasons given for this were that it's bothersome to read written descriptions and the small font size.

The CAA then undertook a number of online experiments to test whether consumers notice marketing disclaimers. One experiment included emphasised claims in 48 point font with disclaimers in 10 point font. Of the consumers that noticed the claims, over $84 \%$ overlooked the disclaimer. Another experiment involved a video where over $91 \%$ of consumers missed at least half of the disclaimers. Another example required consumers to scroll down to see the disclaimer: of the consumers that noticed the claims, over $68 \%$ of consumers missed the disclaimer (58\% blamed the size of the disclaimer and $40 \%$ blamed the need to scroll down).

Key reasons for missing disclaimers included i) use of small font size (in general and compared with the emphasised claim font size); ii) disclaimers not appearing close enough to the emphasised claim; and iii) difficulty in reading disclaimers against a patterned background. In addition, for video marketing, additional issues included i) insufficient time to read the disclaimer; ii) disclaimers not appearing in the same scene as claims; iii) disclaimers only appearing in text form (when claims were read out); and iv) general information overload.

An additional concern raised by the study was that even where consumers did notice disclaimers, many did not understand the meaning of the disclaimer for various reasons. This led some consumers to dismiss the disclaimer entirely.

Source: Consumer Affairs Agency (Japan) (2017 $[47])$.

Consumers are also time poor. Gill Wales Research $\left(2014_{[44]}\right)$ estimated that British consumers spent an average of three to four hours per week engaging with markets in 2014. That included online and offline shopping across the range of consumer products and services. In this context, consumers are time pressured when shopping online and "often feel short of time to deal with problems they face in markets for goods and services" (Citizens Advice, 2016, p. 2[46]).

This has implications for how consumers interact with markets. As noted in the Consumer Policy Toolkit (OECD, 2010, p. 27 $\left.7_{[4]}\right)$ : 
... time-pressured consumers are likely to make key decisions by i) limiting searches; ii) deferring to an intermediary for advice; iii) employing a rule of thumb (i.e. a heuristic technique); or iv) forgoing making a purchasing decision because of the effort that would be required to properly research and evaluate a proposition.

Further, few consumer want to spend more time considering offers in the market. For example, only $1 \%$ of British consumers would choose to spend more time on "shopping and services" if they could (OFT, 2007 $[43]$ ). Further, research by Citizens Advice $\left(2016_{[46]}\right)$ suggests that encouraging consumers to spend more time reading disclosures may be counterproductive. They found that consumers who were prompted to spend more time reading information tended to be less satisfied with their decision than consumers that followed their usual decision making processes (Citizens Advice, 2016 ${ }_{[46]}$ ). However, the research did not test whether consumers made better decisions in terms of price, quality and avoiding problems.

Complexity (rather than just volume) can also lead consumers to disengage or make sub-optimal decisions. This is demonstrated with an experiment undertaken by the EC $\left(2016_{[48]}\right)$ in relation to energy pricing. In the experiment, consumers were presented with either complex or simplified pricing information and asked to choose the best energy deal for them over two rounds. In the first round there was no significant difference between the two forms of pricing. However, in the second round $37 \%$ of consumers with the simple pricing information choose the optimal deal as compared to $22 \%$ consumer with the complex pricing information (a statistically significant difference of 15 percentage points).

Bar-Gill (2012, pp. 18-19 ${ }_{[49]}$ ) argues that some businesses may actually increase complexity purposefully because this:

... hides the true cost of the product from the imperfectly rational consumer ... The imperfectly rational consumer deals with complexity by ignoring it. He simplifies his decision by overlooking non-salient price dimensions ... So while complexity may not faze the rational consumer, it will most likely mislead the imperfectly rational consumer.

In addition, complexity may lead consumers to follow the actions of others without regard to their own information, called "informational cascades", which tends to lead to poor decision making by consumers (Bikhchandi, Hirshleifer and Welch, 1998 ${ }_{[50]}$ ). As noted by Duan et. al., (2009, p. $\left.25_{[51]}\right)$ :

... the abundance of online information does not necessarily benefit consumers. Informational cascades are known to generate suboptimal social allocation ... By providing easily available product ranking information that enables informational cascades, the Internet may decrease rather than increase consumer welfare.

One concrete way in which the problem of information overload may manifest is in consumers choosing not to read online terms and conditions. There is growing evidence and acceptance that most consumers do not read online terms and conditions when making online purchases (see Box 3.3). Indeed, many consumers simply accept online terms and conditions, or scan them briefly, instead of reading them in full. 


\section{Box 3.3. Readership of online terms and conditions}

There is growing evidence that few consumers read online terms and conditions, in part or in full, when making online purchases. Estimates of (at least partial) readership of online terms and conditions vary from $0.2 \%$ to $77.9 \%$ of consumers, depending on the way these are presented, the product or service they relate to, and the way readership is measured.

The EC (2016 $\left.6_{[52]}\right)$ found that while 95 to $100 \%$ of consumers accept online terms and conditions, very few read these in full. Readership varied depending on the presentation of terms and conditions. Where consumers had to click through to terms and conditions, only $9.4 \%$ opened them whereas $77.9 \%$ of consumers said that they at least scanned terms and conditions that could be scrolled through.

Other estimates of readership vary from $4 \%$ (Hillman, 2005 ${ }_{[53]}$ ) to $7 \%$ (for British consumers, see Smithers $\left(2011_{[54]}\right)$ ). Readership of end user licence agreements (EULAs) appears to be even lower with only $0.2 \%$ of consumers accessing EULAs (Bakos, Marotta-Wurgler and Trossen, 2014 ${ }_{[55]}$ ); and Marotta-Wurgler $\left(2011_{[56]}\right.$; 2012 $\left.{ }_{[57]}\right)$ found that requiring consumer consent did little to improve readership of online EULAs.

Levels of readership may vary depending on the type of product or service being purchased. Stark and Choplin (2009 $\left.{ }_{[58]}\right)$ found that only 5\% of consumers said they read terms and conditions for downloading software in full. Where the stakes are higher, however, consumers are more likely to read terms and conditions: the same research found that $72 \%$ of consumers said they read car rental contracts, while $73 \%$ said they read mortgage contracts. In the OECD's recent survey of consumer attitudes towards peer platforms, only $17 \%$ of respondents said they read terms and conditions of peer platforms (such as Uber and Airbnb) in full (OECD, 2017 $\left.{ }_{[59]}\right)$.

There is evidence, however, that this is not due to behavioural biases, but instead represents a reasonable assessment of the costs and benefits of reading (Helleringer and Sibony, 2016 $[60]$; Ben-Shahar, 2008 $\left.{ }_{[61]}\right)$. In particular, reading online terms and conditions is often a time consuming task, as the examples in Figure 3.1 demonstrate. Further, the complexity and jargon contained in most online terms and conditions makes them inaccessible for many consumers (European Commission, 2016 ${ }_{[52]}$ ). Worryingly, online terms and conditions appear to be getting longer and more difficult to understand (Marotta-Wurgler and Taylor, 2013 ${ }_{[62]}$; Warren, 2008 ${ }_{[63]}$ ). In addition, the inability of consumers to negotiate online terms and conditions, especially with larger online businesses, may leave consumers with no real option than to agree to the terms and conditions, in which case there may be little benefit from reading (Ben-Shahar, 2008 ${ }_{[64]}$ ). 
Figure 3.1. Reading online terms and conditions (T\&Cs) is time consuming

\section{8 minutes to read FitBit's T\&Cs}

\section{8 work days}

to read all the privacy notices encountered in a year

\section{0 words of online T\&Cs encountered in a week}

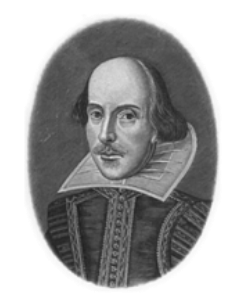

\section{Hamlet}

shorter than PayPal's T\&Cs

MacBeth

shorter than Apple iTunes' T\&Cs

Sources: Parris (2012[65]); Norwegian Consumer Council (2016[66]); McDonald and Cranor (2008[67]) and Hern (2015[68]).

\subsection{Anchoring and framing: context, form and timing matters}

Economic theory says little about how and when information should be conveyed to consumers (except to suggest that consumers need the information before agreeing to a transaction). However, findings from behavioural insights suggest that these issues are of key importance (Tversky and Kahneman, 1981 [69] ). In particular, consumers are susceptible to anchoring and framing effects.

Anchoring occurs when consumers weight one piece of information too heavily when making a decision, often at the expense of other information (Tversky and Kahneman, $1974_{[70]}$; Kahneman, Lovallo and Sibony, 2011 $\left.1_{[71]}\right)$. This can mean that consumers do not value the entire offer properly, even when additional information is provided. This can lead to sub-optimal choices and consumer harm. One common anchor point, especially when consumers are facing difficult decisions (i.e. when consumers are also facing information overload), is price. This can exacerbate other behavioural biases such as framing around price, as discussed below.

Framing refers to the fact that consumers are influenced not only by the content of the information provided by businesses but also by how the information is presented (Tversky and Kahneman, 1981 [69]; Sunstein, 2011 [72]). Hence, presenting an option in a certain way may induce consumers to evaluate the choice from a particular reference point. Indeed, the framing of a decision may even change the decision (King and Smith, $\left.2010_{[73]}\right)$. Several studies have shown that timing, context and frequency of disclosure are important to whether consumers read and comprehend the information being disclosed (FTC, 2016 $[74]$ ).

As part of a study on consumer vulnerability, the EC $\left(2016_{[48]}\right)$ undertook a behavioural study to assess the effect of the prominence of information on consumers' ability to select the best unsecured personal loan for them. While consumers received the same information under the two test conditions, the prominence of the annual percentage rate 
(APR) differed: in one it appeared at the top in large font, in the other it was at the bottom in small font. In both rounds of the experiment consumers with the more prominent APR information performed better (with $91 \%$ of consumers selecting the best loan compared to $82 \%$ in the first round and $88 \%$ versus $82 \%$ in the second round).

Framing (alongside anchoring) can be a particular problem with pricing disclosures. Common pricing practices that have the potential to result in consumer harm are outlined in Box 3.4. In 2010, the OFT undertook an in-depth study on the effects of these various forms of pricing practices ([75]). Of these, it found that the greatest potential to mislead was from drip pricing, followed by time limited offers, bait pricing, complex pricing, reference pricing, and volume and "free" offers. Drip pricing, time limited offers and bait pricing are discussed in more detail in Section 3.3. Reference pricing is discussed below. The effects of complex pricing are similar to the effects of information overload (see Section 3.1).

In relation to volume and "free" offers, these are common practices that can benefit consumers so long as consumers can determine unit prices and businesses do not engage in misleading practices concerning the offer (OFT, 2010 [75]). These practices can generally be assessed under generic consumer protection laws that protect against misleading conduct.

\section{Reference pricing}

Reference pricing occurs where a price is listed next to another "reference" price (either a pre-sale, competitor's or recommended retail price). Reference pricing makes use of anchoring whereby consumers compare the reference price with the sale price to determine the value of the offer (Ahmetoglu, Furnham and Fagan, 2014 ${ }_{[76]}$ ).

Economic theory would suggest that a reference price should not impact a consumer's willingness to pay. However, research shows that consumers are generally willing to pay more when a higher reference price is presented (Kristensen and Gärling, 2000 [77]). In reviewing the literature on the effects of reference pricing, Ahmetoglu et al. (2014, p. $699_{[76]}$ ), concluded that:

... a large body of evidence shows that the presence of a reference price increases consumers' deal valuations and purchase intentions and can lower their search intentions ... Reference prices can, in some instances, influence consumers even when these are very large and consumers are sceptical of their truthfulness.

The inclusion of accurate reference prices that consumers could expect to pay in the market can be useful in conveying information to consumers regarding the value of the offer (OFT, 2010 $\left.0_{[75]}\right)$. However, there is the potential for businesses to distort consumer demand by using inflated or inaccurate reference prices, which can have adverse implications for competition, even if consumers are sceptical about the reference price

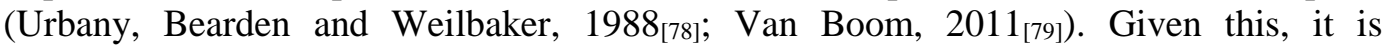
important that businesses only use true reference prices that consumers would be likely to encounter in the market. 


\section{Box 3.4. Pricing practices and behavioural biases}

\section{Drip pricing}

Drip pricing occurs where a company advertises its product at a certain (low) price but later adds on additional non-avoidable fees or surcharges. Drip pricing preys on the anchoring and endowment effects (see Section 3.3). It can result in consumer loss as consumers feel committed to the purchase decision and stick with it despite the price increasing during the transaction process. It can increase purchase intentions, price and value satisfaction and reduce search intentions (Xia and Monroe, 2004 ${ }_{[80]}$ ).

\section{Time limited offers}

Time limited offers may take advantage of consumers' tendency to be loss averse if businesses are able to produce a feeling of scarcity (Ahmetoglu et al., 2010 [81]). Time limited offers are most likely to cause consumer harm where a business provides false or misleading information regarding the time limited nature of the offer.

\section{Bait pricing}

Bait pricing occurs where a business advertises a product at a low price to attract consumers to their store/site but there is only a low volume of products on sale (that sell out) and consumers end up making a more expensive purchase once there. Like drip pricing, this also makes use of the endowment effect (see Section 3.3) and may be detrimental to consumers (Ellison and Fischer Ellison, 2009 ${ }_{[82]}$ ).

\section{Complex pricing}

Complex pricing can result in consumers struggling to determine prices since they depend on multiple factors. The effects of complex pricing similar to that of information overload and may be detrimental to consumers if they are not able to make decisions in their best interests (Ahmetoglu et al., 2010 $[81]$ ). Complex pricing may also prey on consumer overconfidence (see Section 3.5).

\section{Reference pricing}

Reference pricing occurs where a price is listed in reference to another (higher) price. This could be the pre-sale price, a competitor's price, the recommended retail price, or a post-sale price. While economic theory would suggest this shouldn't have any impact, behavioural studies show that reference prices influence consumers' assessment of value and hence, purchase intentions (Ahmetoglu et al., 2010 $[81]$ ).

\section{Volume and "free" offers}

Volume and "free" offers occur where businesses offer a discount for additional items purchased. For example, a business may offer consumers a "buy two, get one free" type offer. This is likely to increase purchase volumes but the net effects for consumers are difficult to determine as they may also confer consumer savings (Ahmetoglu et al., $\left.2010_{[81]}\right)$. 
For this reason, many consumer agencies across the OECD have taken action against businesses that have used inflated or inaccurate reference prices. These types of cases tend to be pursued under generic consumer protection laws that prohibit businesses from providing false or misleading information, rather than specific laws that ban reference pricing. This is discussed in more detail in Section 4.1. In other cases, some agencies, like the US FTC, do not view reference pricing as a priority for enforcement action given the benefits to consumers from aggressive price competition, especially in the online context, where consumers can easily "check the value of the bargain being offered at competing retailers' Web sites, perhaps compare the cost at Amazon.com, and even find out what it might cost to buy the item used on eBay" (Pitofsky, Shaheen and Mudge, 2004, p. 64 ${ }_{[83]}$ ).

\section{Presentation of information}

More generally, behavioural insights have shown that the presentation of information matters. For example, consumers have a tendency to only read text towards the top of long text disclosures (FTC, 2016 $[74]$ ). Businesses could take advantage of this by putting problematic terms further down. Further, Levav et al. $\left(2010_{[41]}\right)$ found that the order of options (and the choice of defaults - see Section 3.4) can have a significant impact on consumer decisions. Format also matters and consumers may be less likely to engage with information in small print, footnotes, new windows and/or scrolling text boxes (European Commission, 2016 ${ }_{[52]}$ ).

In addition, there is evidence that consumer decisions are influenced by the environment in which they make the decision (Darke, Chattopadhyay and Ashworth, 2006 ${ }_{[84]}$ ). For example, transactions made through mobile devices are often undertaken "on the go" where consumers make rapid purchase decisions while in transit. In such a context, the ability of consumers to review terms sufficiently before agreeing to a transaction can be limited. Alternatively, fully understanding the terms and conditions of sale in such a context is likely to time consuming and burdensome (OECD, 2014 $\left.{ }_{[85]}\right)$.

The disclosure medium (text, audio or video) can also influence decision making (Benartzi and Lehrer, 2017 $[5]$ ). Research by Jiang and Benbasat $\left(2007_{[86]}\right)$ suggests that videos (with or without narration) may be more effective for communicating product features to consumers, except for highly complex products. In addition, in the context of advertising, Facebook has undertaken experiments that suggest that advertisements containing images rather than text are more engaging for consumers (Facebook IQ, $2017_{[87]}$ ), as are advertisements on mobile devices compared to television (Facebook, $\left.2015_{[88]}\right)$.

\subsection{The endowment effect: consumers are loss averse}

The endowment effect occurs when consumers demand more to give up an object they own than they would be willing to pay to acquire it. That is, a good becomes more valuable to a consumer once it is part of their "endowment" (OECD, 2017 [2] ). This can be explained by a notion called "loss aversion" (Kahneman, Knetsch and Thaler, 1991 ${ }_{[89]}$ ). As stated by Tversky and Kahneman (1992, p. 298 $\left.{ }_{[90]}\right)$ : "One of the basic phenomena of choice under both risk and uncertainty is that losses loom larger than gains". That is, consumers tend to be loss averse. Drip pricing, bait pricing and time limited offers all take advantage of the endowment effect and loss aversion. 


\section{Drip pricing}

Drip pricing takes advantage of the endowment effect. Once consumers have decided to make a particular online purchase (especially one that involved considerable search time and effort), that decision effectively becomes part of their endowment. That is, in their mind they have already acquired it. If the cost of the purchase then increases due to drip pricing, loss aversion may make it more difficult for consumers to step away from the purchase (OFT, 2012[91]). This could result in consumers making purchases that are not in their best interests; that is, consumers may not shop around enough and may make purchases at higher prices than they would otherwise. Drip pricing can also make it much more difficult for consumers to understand and compare final prices (Greenleaf et al., $\left.2016_{[92]}\right)$.

As mentioned above, the OFT $\left(2010_{[75]}\right)$ found that drip pricing had the worst consumer outcomes of the pricing disclosures it tested. To test the effects of drip pricing it ran a simulated online experiment. It found that, compared to a baseline of no drip pricing, there were 9\% more search errors (due to consumers not searching enough), and 14\% more purchasing errors (where consumer bought too many units). In addition, consumers tended to stick with the first store they visited even when they shouldn't have: in $27 \%$ of cases consumers bought from the first store they "visited" when they shouldn't have, and the first store received $112 \%$ of optimal sales. This experiment shows that drip pricing has the potential to significantly distort consumer decision making, to the consumer's detriment.

Morwitz and Santana (2012[93] $)$ conducted two similar experiments; one in the airline industry and one for rental cars. In the airline experiment, they found that consumers were more likely to buy when faced with drip pricing (that is, disclosure of mandatory fees decreased buying intentions). However, this effect did not hold for experienced consumers. They also found that consumers were more likely to make repeat purchases and buy add-ons if prices were disclosed. The results were similar for the car rental experiment but in that case, even experienced consumers were influenced by drip pricing.

In addition, the EC (2016 $[48])$ undertook a behavioural study to assess the effects of drip pricing on consumers' ability to select the best bundled broadband, telephone and TV package deal for them. In the first round of the experiment $83 \%$ of consumers that received the total price choose the optimal deal as compared to $65 \%$ of consumers that received drip pricing (a statistically significant difference of 19 percentage points). However, in the second round there was no significant difference between the two pricing approaches.

Under economic models with "rational agents", drip pricing may not survive in competitive markets and the outcomes of drip pricing are not always clear (Baye, 2012 [94]). However, if consumers are subject to behavioural biases, then there is potential for substantial consumer detriment (Laibson, 2012[95]). In this case, not only is the potential for consumer detriment high but the ability of competition to correct for this is limited (Gabaix and Laibson, 2006[96]; Oxera, 2013 [97]). With these assumptions, multiple studies have found that drip pricing will persist even in competitive markets (Muir, Seim and Vitorino, 2013 ${ }_{[98]}$; Heidhues, Ko and Murooka, 2016 $\left.{ }_{[99]}\right)$. Another outcome of drip pricing could be that more savvy (or experienced) consumers benefit while more naive (and inexperienced) consumers suffer detriment; this is backed up by the study findings discussed above. Hence, there is also the potential for distributive effects from drip pricing $\left(\mathrm{OECD}, 2012_{[100]}\right)$. 
For these reasons, a number of consumer agencies have required various businesses to change their practices to include all mandatory charges in the headline advertised price. In particular, there have been a number of enforcement actions across the OECD against drip pricing in the online tourism sector, mostly pursued as misleading conduct cases (see Box 3.5). Ways of addressing drip pricing are discussed more in Section 4.1.

\section{Time limited offers}

Time limited offers also take advantage of consumers' loss aversion by evoking consumers' fear that they might miss out on a particular product/service or deal. In addition, time limited offers create the impression of scarcity, which can increase demand (Ahmetoglu, Furnham and Fagan, 2014 ${ }_{[76]}$ ).

Of the pricing practices tested by the OFT $\left(2010_{[75]}\right)$, time limited offers resulted in the second highest level of consumer detriment (after drip pricing). In particular, they resulted in the most purchase errors including consumers buying at the first shop they visited despite there being gains from shopping around.

Given the ability of time limited offers to distort consumer purchasing decisions, it is crucial that businesses only advertise offers as being time limited when this is actually the case (OFT, 2008 $[101])$.

\section{Bait pricing}

Bait pricing takes advantage of the endowment effect in that once a consumer makes a decision to purchase the advertised product/service it effectively becomes part of their endowment. Consumers then tend to stick with a purchase decision even if the product/service is not available at the advertised price. Bait pricing has also been described as taking advantage of consumers' tendency to go through with a decision once the decision is made - the "commitment and consistency" principle (Cialdini, 2006 ${ }_{[102]}$ ).

Ellison and Fisher Ellison $\left(2009_{[82]}\right)$ found that bait pricing had a strong effect on consumer behaviour in the context of an online price comparison site. More generally, the OFT (2010, p. 56 $\left.6_{[75]}\right)$ found that bait pricing can result in consumer detriment and concluded:

Bait pricing has a clear effect on consumers' shopping decisions, most people expect the advertised offer to be available and choose the trader based on the advertised offer. Once they get to the trader and find that the advertised offer is not available a third still purchased a product from the same trader. There are also high levels of emotional detriment in terms of consumers being frustrated and annoyed by the practice.

The OFT believes that the fact that such a high proportion of consumers think that an offer will be available means it is potentially very easy to mislead consumers if an advertisement does not make it clear if a product has very limited availability.

Consequently, a number of jurisdictions have prohibited bait pricing, as discussed in Section 4.1. 


\section{Box 3.5. Drip pricing in the tourism sector}

\section{Airline payment surcharges in the United Kingdom and Australia}

The OFT undertook an investigation of fourteen airline companies after receiving a super-complaint from consumer advocacy body Which? about payment surcharges $\left(2012_{[103]}\right)$. The OFT was concerned that payment surcharges were being used to conceal the true price of airline services as most customers could not avoid this surcharge. This was misleading to consumers and also breached national disclosure requirements. The airlines subsequently changed their pricing and disclosure practices.

The Australian Competition and Consumer Commission $\left(2015_{[104]}\right)$ similarly undertook enforcement action against two airlines for failing to disclose mandatory booking and service fees in headline prices. These businesses were fined for making false or misleading representations and subsequently changed the way they disclosed prices online. More generally, businesses operating in Australia are required to state the total price upfront, which should protect against drip pricing (ACCC, 2017 $7_{[105]}$ ).

\section{Airline pricing in Canada and the United States}

In response to drip pricing practices in the airline industry in Canada, the Canadian government now requires airlines to use all-inclusive pricing, similar to the more general requirements in Australia (Government of Canada, 2013 ${ }_{[106]}$ ). The US also has a Full Fare Advertising Rule, which requires disclosure of the full price, including government taxes/fees and surcharges, in advertising, on websites and on the passenger's e-ticket confirmation. Carriers must also disclose all fees for optional services through a prominent link on their homepage (U.S. Department of Transportation, 14 C.F.R. Part 399.84).

\section{Car hire companies in Canada}

The Canadian Competition Bureau has negotiated settlements with a number of major car rental companies over drip pricing practices that it believed constituted misleading advertising (Competition Policy International, 2017 $[107]$; Milton, 2017 $[108]$ ).

\section{Hotel resort fees in the United States}

In 2012, the FTC warned 22 online hotel booking sites that by excluding certain mandatory fees they may be violating the law by providing a deceptively low estimate of hotel room prices ${ }_{[[109])}$. In 2017, the FTC's Bureau of Economics released a staff report examining partitioned pricing and drip pricing in hotel resort fees. It found that separating mandatory resort fees from room rates without first disclosing the total price is likely to harm consumers by increasing search and cognitive costs and/or by leading consumers to choose a more costly room (Sullivan, $\left.2017_{[110]}\right)$.

\section{Travel comparison and booking sites in Europe}

In 2016, the EC and European Union (EU) consumer protection authorities screened 352 price comparison and travel booking websites across the EU (European Commission, $2017_{[111]}$ ). In approximately one in three cases, there were different prices on the comparison page as compared to the booking page, sometime due to certain fees not being included. 


\subsection{Consumers are susceptible to default settings}

One key lesson from behavioural insights is that consumers tend to stick with the default option (or status quo) rather than actively choosing another alternative or opting-out of the default (Kahneman, Knetsch and Thaler, 1991 ${ }_{[89]}$; Sunstein, 2011 $1_{[72]}$ ). This can potentially lead to consumer harm where consumers choose to stick with a default despite it not being in their best interest.

The issue of default settings has been widely researched across a range of areas including savings plans (Carroll et al., 2009 ${ }_{[112]}$ ), organ donation (Johnson and Goldstein, 2004 $4_{[16]}$ ), retirement plans (Samuelson and Zeckhauser, 1988 $\left.{ }_{[113]}\right)$ and insurance (Johnson et al., $\left.1993_{[114]}\right)$. In reviewing the relevant literature, Ahmetoglu et al. (2010, pp. 13-14 $\left.{ }_{[81]}\right)$ found that:

... people tend to choose the default, for better or worse, even those with major, long-term consequences. This may be due to favouring inaction, avoiding cognitive effort, inferring that the default option is the best recommended, or tending to favour the status quo. The default effect may, therefore, be detrimental for consumers where an opt-out policy is used to get consumers to buy additional products or services they might not necessarily want or need.

Default biases may exacerbate issues related to online disclosures. For example, default settings may opt consumers in for additional services with associated fees or charges through the use of pre-checked boxes or negative option marketing. The effectiveness of pre-checked boxes in influencing consumer behaviour can be demonstrated with an example from Goldstein et al. $\left(2008_{[115]}\right)$ :

A large national railroad in Europe made a small change to its website so that seat reservations would be included automatically with ticket purchases (at an additional cost of one to two euros), unless the customer unchecked a box on the online booking form. Whereas $9 \%$ of tickets included reservations before the change, 47\% did after, earning the railroad an additional [US dollars] $\$ 40$ million annually.

Similarly, default settings are relevant to negative option marketing, which has raised concerns in a number of consumer agencies across the OECD. In an FTC workshop on the topic, panellists "discouraged the use of pre-checked boxes to obtain consumer consent because online research indicates consumers ignore them" $\left(2009\right.$, $\mathrm{p}$. $\left.\mathrm{iii}_{[116]}\right)$. A representative from the National Advertising Division of the Council of Better Business Bureau noted that pre-checked boxes signal that the information is routine or unimportant and hence, they are not an effective way of communicating with consumers (FTC, $\left.2009_{[116]}\right)$.

To the extent that pre-checked boxes or other default settings (including negative option marketing) automatically sign consumers up for additional goods or services, financial commitments, disclosure of personal data, or marketing material, it is likely that a significant proportion of consumers will fail to uncheck these options despite not actually wanting them or agreeing with them. This has a great potential to result in consumer detriment. For example, consumers may be billed for goods or services they don't want, they may unwittingly share personal information, or they may be hassled by unwanted marketing. 


\subsection{Consumers can be overconfident and short-sighted}

Numerous studies have shown that consumers have a tendency to be overconfident, leading them to "overestimate their own abilities or prospects, either in absolute terms or in comparison to others" (Grubb, 2015, p. $\left.9_{[117]}\right)$. Overconfidence could lead consumers to discount the likelihood that they will encounter future problems, which could lead them to accept terms and conditions without reading them. Similarly, overconfidence could lead consumers to dismiss warnings and other negative disclosures, even when they do read them.

As noted by panellists at an FTC workshop on negative option marketing (2009, pp. iiiii $\left._{[116]}\right)$

... many online consumers exhibit certain characteristics, including inattention, unwarranted confidence, exuberance, and a desire for immediate gratification, which make them less likely to see and read disclosures ... as a result ... consumers become "click-happy" and quickly navigate through webpages, without paying much attention because they believe nothing will go wrong and want to complete the transaction as rapidly as possible.

Businesses could take advantage of consumer overconfidence by introducing more complicated pricing structures or contracts that require some affirmative action from the consumer $\left(\mathrm{Grubb}, 2009_{[118]}\right)$. Examples of this include non-automatic post-sale rebates, free trial periods, automatic renewal of contracts, and cash-back incentives (Grubb, $\left.2015_{[117]}\right)$. Where consumers overvalue such contracts due to overconfidence, Grubb $\left(2015_{[117]}\right)$ found that such measures could persist even in competitive markets.

Bar-Gill $\left(2012_{[49]}\right)$ argues that consumer biases such as overconfidence can lead consumers to routinely over or underestimate future usage. For example, a consumer may be optimistic about paying back a loan (or credit card balance) by the due date, thus avoiding interest payments and late fees. If the consumer truly believes this, they might ignore the late fees when comparing loans, only to find later (when they fail to make the payments on time) that they chose the wrong loan given their actual behaviour. If consumers have better information about their likely future use of a service they might make different (i.e. better) decisions (Helleringer and Sibony, 2016 $\left.6_{[60]}\right)$. Indeed, Bar-Gill $\left(2012_{[49]}\right)$ argues that some markets - for example, credit card, mortgage and mobile phone markets - have complex pricing arrangements precisely to take advantage of the difficulties consumers experience in predicting future usage requirements.

The problems associated with overconfidence could be exacerbated by consumer myopia and time inconsistency. Myopia occurs when consumers overly discount costs or benefits that may occur in the future as compared to immediate costs or benefits. This could include time, in that consumers may not invest the time to understand disclosures in full before making a purchase even though it may save them considerable time later (for example, if they make a poor purchase decision which requires them to obtain a refund or make an alternative purchase). Businesses may take advantage of consumer myopia by highlighting immediate benefits in disclosures or hiding future potential costs. Indeed, Bar-Gill $\left(2012_{[49]}\right)$ argues that businesses often include deferred costs in consumer contracts precisely for this reason. One example of this is providing consumers with "free" mobile phone handsets upfront that are (more than) paid off in higher monthly service fees later (Bar-Gill, 2012 $\left.{ }_{[49]}\right)$. 


\subsection{Social norms and cultural factors can also influence outcomes}

In addition, there may be social norms that influence consumer behaviour in relation to disclosures. For example, if a consumer knows that their friends and family use online marketplaces or apps that require agreement with terms and conditions, or privacy policies, they may be more likely to also agree to them, perhaps without reading. Further, a consumer's ability to comprehend online disclosures is likely to be influenced by:

- age and education (Van Deursen, Van Dijk and Peters, 2011 $1_{[119]}$ )

- access to and familiarity with the Internet (Van Deursen and Van Dijk, 2010 $0_{[120]}$ )

- cultural background (Li and Kirkup, 2007 ${ }_{[121]}$ ).

Finally, gender may sometimes be a relevant factor. Hargittai and Shafer $\left(2006_{[122]}\right)$ found that males tended to feel more confident when browsing online (even though they found no significant difference in competence).

Chapter 4 looks at what the behavioural insights discussed in this chapter mean for ensuring effective online disclosure policies. 


\section{Improving online disclosures for consumers}

The purpose of this chapter is to summarise the key policy implications of behavioural insights for improving online disclosures for consumers. These include the importance of:

- clear and accurate information and pricing

- not relying on terms and conditions to convey important information

- express and meaningful consumer consent

- simple information

- using images, audio and video, where appropriate, not just text

- timing (i.e. getting the right information at the right time)

- considering whether disclosures could be improved with personalisation

- use of information by third parties.

More specific insights may be gathered through further testing the effectiveness of specific forms of disclosures on consumers, through behavioural experiments, for example. Testing of online disclosures will be particularly important in markets that are more susceptible to consumer detriment. High-level guidance on testing consumer disclosures is provided in Annex B.

\subsection{Clear and accurate information and pricing}

As discussed in Chapter 2, clear and accurate information is crucial to ensuring that consumers can make informed decisions when shopping online. It is for this reason that most OECD countries have legislation that prohibits businesses from misleading or deceiving consumers, including by providing false or misleading information, or by omitting information.

A number of pricing practices discussed in Chapter 3 also fundamentally relate to concerns about misleading consumers. This could be in relation to what price consumers will pay, or the value of the deal they are getting. In particular:

- Drip pricing practices may mislead consumers about the final price that they will have to pay.

- Time limited offers may mislead consumers about the scarcity of the deal to the extent that the offer is not actually time limited.

- Bait pricing may mislead consumers into thinking they will get a deal when there is little chance of this due to the low volume on offer.

- Reference pricing may mislead consumers about the value of the deal if the reference price is not realistic.

- Volume or "free" offers may mislead consumers if these deals do not actually represent savings for consumers.

Policymakers can protect consumers against these types of practices either under generic false or misleading practices prohibitions or under more specific prohibitions. Both of these approaches are employed across the OECD (see Box 4.1). 


\section{Box 4.1. Responses to misleading pricing practices}

\section{Enforcement actions under general false or misleading information protections}

The Lithuanian Competition Council $\left(2015_{[123]}\right)$ fined an online electronics company for misleading consumers by displaying sale prices against fake reference prices.

Similarly, five United Kingdom furniture and carpet retailers changed their pricing practices after an OFT $\left(2014_{[124]}\right)$ investigation highlighted concerns about the use of fake reference prices.

The ACCC $\left(2016_{[125]}\right)$ has taken enforcement action against an online clothing retailer for using unrealistic reference prices.

\section{Prohibitions against misleading pricing practices}

Bait pricing or bait and switch practices are prohibited in Australia (s. 34, Australian Consumer Law), Canada (s. 74.04, Competition Act), the EU (European Commission, 2016 $\left.{ }_{[126]}\right)$, New Zealand (New Zealand Commerce Commission, 2015 $5_{[127]}$ ) and the US (Part 238, Title 16, Code of Federal Regulations).

Drip pricing is effectively prohibited in Australia as businesses are required to provide consumers with a single upfront price which effectively counters attempts at drip pricing (s. 48, Australian Consumer Law). Similar requirements exist for pricing in the airline industry in Canada and the US (see Box 3.5).

Canada has a number of other prohibitions on certain price-related representations including regarding the ordinary selling price of goods (to prevent misleading reference pricing), sales at prices above those advertised, and double ticketing (where there are multiple prices advertised and the lowest price is not charged) (Competition Bureau (Canada), 2017 $[128]$ ).

There are also restrictions on the use of time limited offers in the United Kingdom (OFT, $\left.2008_{[101]}\right)$.

\section{Guidance material}

While not binding, the ACCC has published guidance on its website to encourage businesses to ensure their reference pricing practices are not misleading $\left(2017_{[129]}\right)$.

The E-commerce Recommendation (OECD, 2016 $6_{[3]}$ ) and the Consumer Policy Guidance on Mobile and Online Payments (OECD, 2014 $\left.{ }_{[85]}\right)$ both recommend that businesses provide clear pricing information by including all fixed charges in headline prices.

\subsection{Important information should not be buried in the terms and conditions}

There is clear evidence that few consumers read online terms and conditions in any detail. What is less clear is what should be done about this. Is the fact that few consumers read terms and conditions a problem? Should the goal be to increase readership of online terms and conditions? Should policymakers instead accept that consumers rarely read online terms and conditions and look at other ways to ensure they are informed and protected? Or should policymakers use a combination of these two approaches? 
There is evidence that online terms and conditions could be improved to increase readership and understanding. For example, the EC $\left(2016_{[52]}\right)$ found that shortening and simplifying terms and conditions enhanced readability and improved consumers' understanding of and trust in terms and conditions, without making them feel like they had missed material information. The EC also found that forced exposure to terms and conditions can greatly increase readership. Other successful measures to improve readership of online terms and conditions included the use of "reading time" cues (which told consumers that it would take less than five minutes to read the terms and conditions) and "trust marks/seals" to increase effortless trust and purchase intentions (European Commission, 2016 $[52])$.

It has also been suggested that consumer comprehension of terms and conditions could be improved by placing the most important and unexpected information towards the top of any terms and conditions (FTC, 2016 $[74]$ ). Similarly, the United Kingdom Government has suggested the following strategies for improving online terms and conditions:

- presenting key terms in bold and upfront

- ensuring that online terms and conditions are succinct and device appropriate (for example, only running to two screens on a smartphone)

- having terms and conditions open automatically before consumers confirm a purchase

- using tagging, so that key information can be found by clicking on the links (Department for Business Innovation \& Skills (United Kingdom), 2016[130]).

In addition, a number of options for improving comprehension of online terms and conditions are discussed in the literature. For example, by rating terms and conditions (Ben-Shahar, 2008 ${ }_{[64]}$; Marotta-Wurgler, 2009 ${ }_{[131]}$ ), using labelling (Choe et al., 2013 ${ }_{[132]}$; European Commission, 2016 ${ }_{[52]}$ ), using condensed warning boxes to highlight the most unexpected and unfavourable terms (Ayres and Schwartz, 2014 $4_{[133]}$ ), or a government sponsored consumer feedback platform (Becher and Zarsky, 2008 $[134]$ ).

There is an open question as to whether these options would substantially increase consumer readership and understanding of online terms and conditions. Even if these improvements were made, consumers may still choose not to spend time reading online terms and conditions, especially if they are not able to negotiate them. For this reason, it is possible that the benefits of policies to change the disclosure of online terms and conditions at a wholesale level might not outweigh the costs. However, policies to improve the disclosure of terms and conditions in specific scenarios where policymakers have linked disclosure issues relating to online terms and conditions to substantial consumer detriment, may be warranted.

Some agencies appear to have accepted that many consumers do not read terms and conditions and are interpreting their laws on this basis. In particular, the United Kingdom's Competition and Markets Authority (CMA, 2015, p. 122 $2_{[135]}$ ) has stated that consumers cannot be excluded from protections against unfair contract terms simply because they have ticked a box saying they have read and agree with a company's terms and conditions:

Declarations that the consumer has read and/or understood the agreement give rise to special concerns... Including a declaration of this kind in a contract effectively requires consumers to say that these conditions have been met, whether they have or not. This tends to defeat the purpose of the [EU Consumer Rights] Directive, and as such is open to serious objection. 
In practice consumers often do not thoroughly read standard written contracts. There is no justification for requiring them to say they have done so whether they have or not. The purpose of 'a read and understood' declarations is clearly to bind consumers to wording regardless of whether they have any real awareness of it. Such statements are thus open to the same objections as provisions binding consumers to terms they have not seen at all ...

One related area is consumer readership and understanding of privacy policies. The FTC $\left(2009_{[136]}\right)$ took enforcement action against Sears for engaging in unfair and deceptive practices by failing to adequately disclose to consumers the scope of personal information collected by its software application. The FTC alleged that this practice violated the Federal Trade Commission Act even though Sears did provide details about the functioning of the application and the collection of information in a "Privacy Statement and User License Agreement", (PULSA) which users were required to consent to before downloading the software application. As the FTC alleged, the PULSA, and the material information about the software application's functions and tracking, only appeared in a "scroll box" that displayed ten lines of the multi-page document at approximately the 75th line down in the scroll box. The decision and order settling the FTC's charges provided that: "Sears is prohibited from including material disclosures only in a privacy policy or user license agreement". Commentators have observed that the FTC's settlement appears to recognise the limitations of online terms and conditions (and privacy policies) for communicating important information to consumers (Gindin, $2009_{[137]}$.

That is not to say that online terms and conditions do not have any use. In particular, use of standard terms and conditions can reduce transaction costs and prices more generally as businesses are able to limit their liabilities. In addition, online terms and conditions may still serve a purpose in:

- providing more information to those consumers that wish to access it, which could potentially be assessed with assistance from technology-enabled third parties (see Section 4.8)

- guiding consumers in the event that they encounter a problem

- allowing enforcement agencies to monitor compliance with the law, and in particular, to ensure that terms and conditions do not breach laws against unfair terms and conditions. ${ }^{4}$

In summary, while online terms and conditions serve a purpose, they should not be the primary means for communicating important information to consumers.

The fact that few consumers actually read most terms and conditions in full may also have implications for the quality of terms and conditions. In particular, as noted by Luth $\left(2010\right.$, p. $\left.164_{[138]}\right)$ :

Consumer rational apathy and adverse selection are likely to result in consumer contract terms that are overly one-sided, favouring the seller over the consumer. The quality of terms can be said to be too low, and this problem is unlikely to be corrected through market instruments ...

In particular, if few consumers actually engage with online terms and conditions, this is unlikely to be an area where businesses actively compete for consumers. Assuming that it is more costly to provide terms and conditions that are more favourable for consumers, the lack of consumer engagement could lead to terms and conditions that are biased towards the business. While this may also reduce costs and hence, prices, this could lead 
to consumer detriment if the resulting terms and conditions place an unfair burden on consumers. This provides an additional justification for governments to ensure that consumers are protected against unfair contract terms and conditions, especially in standard form contracts where consumers have no ability to negotiate terms and conditions.

\subsection{Express and meaningful consumer consent}

The effect of default settings on consumer decision making was discussed in Section 3.4. In particular, it is widely accepted that consumers will often leave pre-checked boxes checked and hence, this is not an effective way to obtain meaningful consumer consent. Negative option marketing strategies similarly prey on default biases and do not provide for meaningful consumer consent.

In recognition of the potentially serious consumer detriment that can occur from default options, the EU has banned pre-ticked boxes online under its Consumer Rights Directive $\left(2011_{[37]}\right)$. The EC did not undertake a specific trial before banning pre-checked boxes since "available evidence was considered compelling enough to support the policy initiative" (Sousa Lourenço et al., 2016, p. 16 ${ }_{[139]}$ ). Similarly, British consumers are not bound by charges for any goods that are sold by way of pre-ticked boxes (The Consumer Contracts (Information, Cancellation and Additional Charges) Regulations 2013).

Under the US Restore Online Shoppers' Confidence Act (ROSCA), which was enacted in 2010, businesses are required to obtain a consumer's express consent before charging for any goods or services purchased online. In addition, for online goods or services sold through a negative option feature (such as a continuity plan, "free trial" conversion, or automatic renewal program) businesses also have to provide consumers with details of the transaction and a simple means to opt-out of any reoccurring charges. The FTC has brought nearly a dozen law enforcement actions alleging violations of ROSCA, as well as other enforcement actions against businesses using negative options features under other laws and rules such as the Federal Trade Commission Act and the Telemarketing Sales Rule.

Similarly, automatic renewal of contracts, which preys on consumers' status quo biases, have been viewed unfavourably by a number of consumer agencies across the OECD and in many cases have been found to be unfair practices, and hence, unlawful (Kovač and Vandenberghe, $\left.2015_{[140]}\right)$.

To the extent that businesses are signing consumers up to incur future fees or charges (monetary and otherwise), they should seek and obtain express and meaningful consumer consent. Pre-checked boxes and negative option marketing strategies are not sufficient for inferring consumer consent.

\subsection{Simple information}

The behavioural insights literature raises serious doubts about consumers' ability to process vast quantities of information. This has implications for policies that mandate information disclosure. As noted by King and Smith (2010, p. 83 $\left.{ }_{[73]}\right)$ :

... consumer policy is often concerned with situations where consumers appear to face an information deficiency. An obvious policy suggestion in such a situation is to increase the availability of, and access to, information. However, if consumers face "choice overload" or other factors that prevent them from taking 
full benefit of available information, increasing the amount of information is unlikely to lead to a better outcome. Indeed it might make matters worse.

Hence, policies that require online businesses to provide extensive quantities of information to consumers have the potential to do more harm than good. In particular, such policies are more likely to result in consumers sticking to the status quo, limiting the number of decision criteria they consider (by, for example, focussing exclusively on price at the expense of other factors such as quality), or engaging in herd behaviour. These actions have potentially detrimental consequences for consumers and the effective functioning of markets.

An experiment by staff from the FTC provides some strong evidence of the potential for disclosure requirements to lead to worse outcomes for consumers (Lacko and Pappalardo, $\left.2004_{[141]}\right)$. The study showed that including information about mortgage broker costs (and hence, their incentives) actually reduced the number of consumers who could identify the cheapest loan. The proportion of consumers who could identify the cheapest loan dropped from over 95 per cent when the broker's commission was not disclosed, to between 49 and 71 per cent (depending on the type of disclosure used). In this case, a policy proposal that was intended to improve consumer decision making by revealing a broker's incentives would have resulted in worse outcomes for consumers.

Requiring businesses to provide vast quantities of information to consumers also has the potential to influence the way in which businesses approach online information disclosures. For example, it may mean that businesses approach the requirement from a mind-set of regulatory compliance rather than trying to provide the information in a way that works for consumers. This might be especially problematic for businesses that are subject to numerous general and sector-specific information disclosure requirements. If businesses concentrate more on compliance than communication, this might reduce the effectiveness of online disclosures as businesses might just list the information without thinking about the best way in which to communicate it to consumers.

Helberger $\left(2013_{[142]}\right)$ cites a number of examples of online businesses that have made an impressive effort to develop consumer-friendly privacy disclosures, the form of which is largely unregulated. In particular, in these examples the companies tend to use more userfriendly language and more engaging layouts (i.e. more colour, clearer headings, and different font styles, sizes and colours). She contrasts these with terms of service sites from the same businesses and finds that these are generally much less consumer friendly (e.g. they tend to use more technical language and more plain text). This may be for a number of reasons, not just differences in regulatory requirements. It may be that these businesses have recognised that privacy is important to consumers and hence, have invested in improving disclosures in this area. It may also be that these businesses are responding to a threat of more regulation by being pro-active in relation to privacy disclosures. Either way, what is does demonstrate is that online businesses are able to create more effective online disclosures when they consider this to be in their interests. Given this, governments should be careful to ensure that any mandated disclosure requirements do not hinder businesses' ability to develop effective disclosures for consumers.

More generally, policymakers should limit the prescriptiveness and extensiveness of any mandated disclosure requirements to the minimum necessary. This alone should improve simplicity. Simplification of disclosure requirements should improve consumer understanding and limit the potential for information overload. Another way to simplify information is to use layering, as discussed below. Done properly, layering should 
substantially reduce the amount of information that online consumers are confronted with when shopping online.

\section{Layered information}

One way to improve information disclosures is through a layered approach. Layering of information involves distilling the information into key headings with short summaries and providing links to consumers who want to know more on each topic. Layering of information can thus reduce the volume of information that is disclosed to the consumer at the point of sale, which can reduce the potential for consumers to face information overload. It is also easier for consumers to navigate, allowing consumers to concentrate their attention on the issues that are of most importance to them.

The online environment, where text can incorporate active links to more information, is well-suited to layering information. As noted by the Productivity Commission (2008, p. $\left.267_{[29]}\right)$ :

... the ability to provide and tailor information through electronic means, including interactive web pages and other web based tools, arguably offers more effective disclosure to individuals with access to a computer ...

However, Garrison et al. (2012, p. $\left.228_{[143]}\right)$ caution that:

Layering of information needs to be done carefully and thoughtfully. Researchers and policymakers need to identify the key pieces of information that are essential to consumer understanding and usability and make sure those pieces are located together in a highly visible place and format.

One area in which substantial work has been undertaken to improve disclosures through layering is in respect of privacy notices. For example, a multi-layered approach to privacy notices was recommended by the OECD over a decade ago (OECD, 2006 ${ }_{[144]}$ ). (For examples of the layering of privacy notices, see Annex D of OECD $\left(2006_{[145]}\right)$.)

\subsection{Use of images, audio and videos and general layout}

The online environment offers businesses a wide variety of options for communicating with consumers. While text is often the default option; images, audio or video are often more effective for communicating with consumers (Zhenhui and Benbasat, 2007 $[86]$; Benartzi and Lehrer, 2017 $[5]$ ).

Box 4.2 provides a summary of the outcomes of an experiment which compared the effectiveness of various disclosures in the context of an online purchase of digital content. The experiment found that the use of emotive graphic warnings aided consumer comprehension. It also highlighted the importance of individual characteristics on comprehension as participant age was a determining factor in the effectiveness of the various forms of warnings. This emphasises the importance of consumer testing of various forms of disclosures (see Annex B). 


\section{Box 4.2. Using warnings to prevent incompatible digital product purchases online}

\section{Experiment by the Joint Research Centre, EC}

The EU Consumer Rights Directive (2011/83/EU) requires businesses to provide consumers with pre-contractual information on the functionality and interoperability of digital products. However, this does not necessarily lead consumers to read and understand this information. One potential error that can occur is that consumers purchase a digital product that does not work with their device(s) and/or system(s).

Esposito et al. $\left(2017_{[146]}\right)$ undertook a computerised lab experiment to test the effectiveness of various "nudges" in ensuring that consumers do not purchase incompatible digital products online. In particular, they looked at the effectiveness of:

- warnings (no warning, a traditional warning, or an emotive warning)

- the style of information (text or logo)

- the timing of the information provision (on the product information page, or on the checkout page).

They also looked at how socio-economic characteristics (age, education and gender) influenced the results.

Overall, the results suggested that only two nudges were effective in reducing the number of incompatible purchases: the emotive warning message (as opposed to no warning message), and placing compatibility information on the checkout page (rather than the product description page).

Interestingly, a traditional warning message had no effect overall (i.e. the same effect as no message), and the style in which the compatibility information was presented (i.e. text or logo) also had no effect overall.

Participant age was a key factor; with older participants tending to make more incompatible purchases (education and gender did not affect the results). The effectiveness of the various nudges was also influenced by age. The number of incompatible purchases by older participants actually increased with emotive warnings and having information at the checkout (rather than on the product information page), the opposite of what was found for participants overall. Further, logos tended to be more effective than text for older participants (but had no effect overall). This suggests that age can be a key factor when determining which nudges work best for online consumers.

Even when using text, there are options about text size and colour, for example. As noted by Sunstein $\left(2014\right.$, p. $\left.586_{[147]}\right)$ "Large fonts, bold letters, and bright colors can be effective in triggering people's attention". Otherwise there is a risk that consumers will simply not read the text (for example, see the report of the Gallup Organisation $\left.\left(2013_{[148]}\right)\right)$. Moreover, Garrison et al. $\left(2012\right.$, p. $\left.228_{[143]}\right)$ note that "contextual framing, visual hierarchy, information sequencing, font choice, white space, and many other design features are critical factors in the success of consumer disclosures". For example, a study by staff at the FTC suggests that text colour, placement and size can influence consumer recognition of native and search advertising (Box 4.3). Further, online presentation of information is discussed at length in Benartzi and Lehrer's $\left(2017_{[5]}\right)$ book "The Smarter Screen: Surprising Ways to Influence and Improve Online Behavior". 


\section{Box 4.3. Recognition of search advertising and native advertising}

In 2017, the FTC released a staff report exploring consumer recognition of paid search advertising and "native advertising" $\left.{ }_{[149]}\right)$. The report summarises the key findings of a piece of commissioned research undertaken in 2014-15. In particular, 48 participants were observed, interviewed, and had their eye movements tracked as they interacted with eight different sets of webpages in a usability lab. Four of the webpages were actual webpages, and the other four were copies with the advertising disclosures modified to be more in keeping with relevant FTC staff guidance (see FTC $\left(2013_{[150]}\right)$ and FTC $\left.\left(2015_{[151]}\right)\right)$. In addition, four of the webpages were desktop sites and four were mobile sites.

Modifications to the advertising disclosures included:

- changing the background colour and using borders to identify different online content (i.e. to make advertised content look different)

- increasing text size and using contrasting colours for the disclosures (i.e. for labels such as "Advertising" and "Ads")

- better placement of disclosures so it is clear what they relate to and so that they are not missed (e.g. for English speakers, disclaimers that appear in the top left of the advertisement are less likely to be missed)

- use of consistent and clear terminology (i.e. "Advertising" and "Ads" as opposed to "Sponsored" or "Paid Content").

After being shown each webpage, respondents were asked indirect questions to determine whether they could identify the advertising content. Because several modifications were made to each disclosure, the effect of each individual modification could not be determined given the small sample size. However, in general, the respondents were better able to identify the advertisements in the modified webpages $(68 \%$ of respondents compared to $47 \%$ of respondents for the original webpages). Another interesting finding was that there was no correlation between the amount of time a respondent spent looking at an advertisement and their recognition of the advertisement. The paper recommended further research to determine the effect of individual modifications.

In summary, there are multiple ways to present information to consumers online. In developing regulation or guidance on online information disclosures, governments should ensure that they do not unnecessarily restrict the ways in which businesses can present information online. Similarly, businesses should consider alternative ways to present key information to consumers. The testing of webpages by businesses can be relatively low cost and can have a significant impact on consumer satisfaction (Benartzi and Lehrer, $\left.2017_{[5]}\right)$. Further, in areas where information disclosure raises particular policy concerns, approaches to disclosure should be tested with consumers before being implemented (Productivity Commission, 2008 ${ }_{[29]}$ ) (see Annex B).

\subsection{Timing of disclosures and use of reminders}

Another key issue for governments and businesses to consider is when to provide information to online consumers. The timing of disclosures can influence their effectiveness (Campbell, Mohr and Verlegh, 2013 ${ }_{[152]}$; Esposito et al., 2017 [146]; FTC, 
2016 $[74]$; McDonald and Lowenthal, 2013 [153]; Benartzi and Lehrer, 2017 $\left.{ }_{[5]}\right)$. It is not surprising that timing is important given that behavioural biases such as the endowment effect and commitment effect may limit the usefulness of some information if it is provided after a consumer has already decided to make a purchase.

In most cases, businesses provide information to consumers before they make a purchase (which can be a mandated requirement for some information). However, in other circumstances, for example, where consumers have an ongoing contract with a provider, timely reminders may be more effective than relying on the information that was provided before (or at the time) the contract commenced. For example, reminding consumers of call rates via a text message when consumers enter a new country is likely to be of particular benefit to consumers who may otherwise have found it difficult to determine what charges they would be liable for (Helleringer and Sibony, 2016 $\left.{ }_{[60]}\right)$.

Similarly, an email, app or text message to remind a consumer of an upcoming bill, contract expiration or renewal date, or changes to the terms and conditions of their contract, are likely to be more successful than relying on consumer memory or pro-active monitoring of contract terms and conditions. This will especially be the case if such reminders are framed in a way that can help and effectively alert consumers. For example, the United Kingdom Financial Conduct Authority (FCA) (2015 $\left.{ }_{[154]}\right)$ found that, while annual statements had no effect on unarranged overdraft charges, text alerts and mobile banking apps substantially reduced monthly unarranged overdraft charges (see Box 4.4).

The importance of timing is likely to vary by market. Further, consumers may have different preferences for when certain information should be made available (McDonald and Lowenthal, 2013 ${ }_{[153]}$ ). As such, timing is something that should be considered on a case-by-case basis, ideally through consumer testing (see Annex B), and by taking into consideration and mapping the critical decision points for consumers where certain information would be particularly useful and relevant (OECD, 2016 $\left.{ }_{[12]}\right)$.

\subsection{Personalised disclosures}

Consumers are heterogeneous; they have different characteristics, different needs, and different preferences. Consumers can even differ in disclosure preferences. In relation to privacy disclosures on mobile devices, for example, McDonald and Lowenthal (2013 $\left.{ }_{[153]}\right)$ found that over half of respondents only wanted to see privacy disclosures before making a purchase, around one in five wanted to see them each time data was collected, and one in ten never wanted to see them.

This suggests that disclosures could be made more effective if they were personalised. This could be done by consumers stating preferences to a business and subsequently being shown only information that they want to see, or by businesses tailoring disclosures based on what they know about the consumer (for example, omitting information that is known to be irrelevant to the consumer) (Benartzi and Lehrer, 2017 ${ }_{[5]}$ ). 


\section{Box 4.4. Annual statements, text alerts, mobile apps and banking behaviour}

In 2015 the FCA, in collaboration with the OFT, undertook a study to understand the impact of various current account disclosures on consumer behaviour (FCA, 2015 [154]). United Kingdom banks disclose current account information to customers in various ways, including through:

- Annual summaries, which were adopted by the banks voluntarily after an OFT market study recommendation in 2008.

- Text alert services, which have been required since 2012 for major banks.

- Mobile banking apps for smartphones, which have been voluntarily adopted by the major banks for commercial purposes.

The FCA was interested in the effect of these different forms of disclosure on a consumer's propensity to incur overdraft charges, change balance levels or switch banks. To assess this, it applied econometric techniques to over 300 million observations from two of the big United Kingdom banks. It found that:

- Annual summaries, as designed by the banks in question, had no effect on consumer behaviour.

- Signing up to text alerts or mobile banking apps reduced the amount of unarranged overdraft charges by $5 \%$ to $8 \%$, respectively.

- Signing up to both services had an additional effect, resulting in a total reduction of $24 \%$.

It hypothesised that the "additional impact of the combination of both services showed the benefit of receiving information upon automatic triggers, without having to actively acquire it, as well as the facility to act quickly upon receiving information" (FCA, 2015, p. $\left.3_{[154]}\right)$.

Bar-Gill $\left(2012_{[49]}\right)$ suggests that personalisation, alongside simplification, could be used to improve comparison shopping in complex markets. For example, for mobile phone services, businesses could be required to disclose the total annual cost of each plan for each individual, taking into account call rates, data rates and the consumer's use. To do this, the business could access data on the consumer's use, provide usage estimates based on the usage of an average consumer, or alternatively, provide an estimate based on the use of a consumer with similar characteristics to the consumer (for example, similar demographic characteristics). Those characteristics could be provided by the consumer or the business could produce an estimate based on what they know about the consumer.

Interestingly, in a study for the $\mathrm{EC}$, it was found that disclosing individualised pricing information for bank accounts actually had a negative impact on rational switching behaviour (TNS, 2012 ${ }_{[155]}$ ). It was hypothesised that this was due to the individual pricing information containing too much information and resulting in information overload. Hence, the form, content and design of any information disclosures remains fundamentally important to ensuring effective disclosures and any prescriptive disclosure requirements should be consumer tested prior to implementation (see Annex B).

Another example where disclosures could be easily personalised is in respect of retail goods that cannot be shipped to the consumer's location (Helleringer and Sibony, 2016[60] $)$. Currently, a consumer can spend a lot of time deciding what to buy from an 
online retailer only to find when entering their delivery address that the retailer does not ship there. This is despite the fact that many businesses know the consumer's location from the moment the consumer goes on their website. A small disclosure such as a pop-up when the consumer first goes on the online shop's webpage to warn the consumer that they do not ship to their location could be of benefit to the consumer at minimal cost to the business.

Personalisation could also be used to ensure that consumers are not provided with irrelevant information. For example, warnings that are only relevant to a particular sub-set of consumers could be withheld for consumers that are not in that sub-set.

In this way, personalisation could potentially be used to improve disclosures for consumers. Sunstein $\left(2013_{[156]}\right)$ has considered the topic of personalising default settings in depth. More relevantly, Porat and Strahilevitz $\left(2014_{[157]}\right)$ make strong arguments for personalising disclosures. However, personalising disclosures is not straightforward and may raise other issues such as privacy and discrimination. This is an area that merits further research.

\subsection{Technology-enabled information provision}

In more complex markets, consumers might need to interact with more substantial amounts of information in order to make good decisions when shopping online. In these markets, consumers might make use of comparison sites or other types of algorithm-based platforms or applications. Private and public online comparison sites have emerged in a number of consumer markets including for:

- Various forms of insurance, including home, car, travel, health and life insurance.

- Energy providers, including electricity and gas providers.

- Telecommunications services, including mobile phone plans, Internet plans and bundled offers.

- Financial products, including mortgages, credit cards, loans and savings accounts.

- Travel services including hotels, flights, and train and bus services.

And there are many other examples of generic online comparison sites. In 2008, Ipsos MORI found that almost half of the British consumers surveyed used price comparison sites $([158])$.

Where consumers have detailed usage information (for example, a previous bill) comparison sites may be able to use this information to determine their best deal. For example, the Australian Government has developed the "Energy Made Easy" site to allow Australian consumers to compare energy deals based on a recent energy bill ([159]). Even where consumers do not have usage information, comparison sites may provide an estimate based on inputs from the consumer. On the Energy Made Easy site, for example, an estimate is generated on the basis of a number of inputs from the consumer (e.g. type of dwelling, number of occupants, and whether there is a swimming pool).

Comparison sites, apps and online platforms can also make use of other information about the consumer to offer new services. For example, comparison sites could use a consumer's past actions to inform the possibilities provided in the future. With the rise of the Internet of Things, there will be more and more opportunities for consumer information to be used to inform future purchasing decisions.

Comparison sites and other intermediaries can also aggregate and display information from other consumers, such as ratings and reviews. This is quite common for booking 
services for restaurants and hotels, for example. In this way, the scope for intermediaries and other applications to use information from various sources to assist consumers when shopping online is substantial.

Gal and Elkin-Koren $\left(2017_{[160]}\right)$ envision a world in which algorithms can do everything for the consumer, from identifying the need for something to be purchased, selecting the best deal and even ordering and paying for the good or service online. While the development of algorithmic consumers is in its infancy, online price comparison sites that rely on algorithms to suggest the best deals for consumers are well established. In addition, new products to assist consumers online are continually being developed. For example, tools to assist consumers in navigating online terms and conditions are already on the market. For example, EULAlyzer is marketed as a tool to help consumers identify potentially problematic terms and conditions in end user license agreements (EULAlyzer, $\left.2017_{[161]}\right)$.

Further, "privacy managers", which are usually available as apps, are already being developed with promising results: see Almuhimedi et al. $\left(2014_{[162]}\right)$; Balebako et al. $\left(2017_{[163]}\right)$ and FTC $\left(2016_{[74]}\right)$. Indeed, researchers from Switzerland's Federal Institute of Technology at Lausanne, the University of Wisconsin and the University of Michigan, recently announced the release of Polisis; a website and browser extension that uses machine learning to automatically read and make sense of online privacy policies for consumers (Greenberg, 2018 $8_{[164]}$ ). It does so by presenting the policy as a graphic flow chart which identifies the type of data collected, where the data could be sent, and whether a consumer can out of that collection or sharing. There is also a chat interface which answers specific questions about a privacy policy.

A key issue for information disclosure is to recognise that the type and form of information that algorithms need is very different from what consumers need. In particular, while consumers need information to be as simple as possible and may not respond to long text and numbers, algorithms tend to work better with detailed information in text or numeric form. Policymakers and businesses should be aware of these two contrasting uses for information and should facilitate the development of different forms of disclosure to meet these two very different needs.

\subsection{Summary of key policy implications}

The key policy implications from this chapter can be summarised as follows:

- Governments should be wary of exacerbating information overload when setting mandatory information requirements for businesses. Governments should also bear in mind the importance of form and context in developing such requirements. In particular, governments should consider not just what information consumer need but also when is the best time for consumers to receive such information, and in what form. Before introducing or changing disclosure requirements, governments should test these with consumers where possible.

- Governments should ensure that consumers are protected from false and misleading information, both online and off. This includes misleading pricing practices such as drip pricing and bait pricing, and the framing of pricing and offers that consumers cannot easily process.

- Businesses should not rely on terms and conditions to communicate material information to consumers. Such information should be presented to consumers at 
a relevant stage of the decision making process and in a clear and salient way. In the case of standard form contracts, governments should ensure that consumers are protected from unfair contract terms since few consumers read terms and conditions and in any case have no ability to negotiate these.

- Personalisation of disclosures could improve consumer comprehension but could also raise new consumer issues. This is an area that would benefit from more research.

- For more complex products and services (e.g. financial products and services, telecommunication services and energy services), including those with usage based pricing, consumer access to information (including on usage) in a machine-readable form should assist comparison shopping and facilitate switching, potentially with the help of intermediaries. 


\section{Annex A. Relevant sections of the E-commerce Recommendation}

Provisions relevant to behavioural insights and online disclosures are reproduced below. Paragraph numbering replicates that in the E-commerce Recommendation (OECD, 2016 [3]).

\section{Online Disclosures}

\section{General Principles}

25. Online disclosures should be clear, accurate, easily accessible and conspicuous so that consumers have information sufficient to make an informed decision regarding a transaction. Such disclosures should be made in plain and easy-to understand language, at a relevant time, and in a manner that enables consumers to retain a complete, accurate and durable record of such information.

26. When more than one language is available to conduct a transaction, businesses should make available in those same languages, all information necessary for consumers to make an informed decision regarding a transaction. All information that refers to costs should indicate the applicable currency, unless it is apparent from the context.

27. Businesses should take into account the technological limitations or special characteristics of a device or platform, while providing all necessary information.

\section{Information about the Business}

28. Businesses engaged in e-commerce with consumers should make readily available information about themselves that is sufficient to allow, at a minimum: (i) identification of the business; ii) prompt, easy and effective consumer communication with the business; iii) appropriate and effective resolution of any disputes that may arise; iv) service of legal process in domestic and crossborder disputes; and v) location of the business.

29. This information should include the legal name of the business and name under which it trades; its principal geographic address; an e-mail address, telephone number or other electronic means of contact; appropriate domain name registration information for web sites that are promoting or engaging in commercial transactions with consumers; and any relevant government registration or license information.

30. When a business publicises its membership in any relevant self-regulatory programme, business association, dispute resolution organisation or other body, the business should provide sufficient information to enable consumers to easily contact such body. Businesses should provide consumers with easy methods to verify that membership, access the relevant codes and practices of the organisation, and take advantage of any dispute resolution mechanisms offered by the organisation.

\section{Information about the Goods or Services}

31. Businesses engaged in e-commerce with consumers should provide information describing the goods or services offered that is sufficient to enable consumers to make informed decisions regarding a transaction. 
32. Depending on relevant factors, including the type of good or service, this should include information such as:

i) Key functionality and interoperability features;

ii) Key technical or contractual requirements, limitations or conditions that might affect a consumer's ability to acquire, access or use the good or service;

iii) Safety and health care information; and

iv) Any age restrictions.

\section{Information about the Transaction}

33. Businesses engaged in e-commerce should provide information about the terms, conditions and costs associated with a transaction that is sufficient to enable consumers to make an informed decision regarding a transaction. Consumers should be able to easily access this information at any stage of the transaction.

34. Businesses should provide consumers with a clear and full statement of the relevant terms and conditions of the transaction.

35. Where applicable and appropriate given the transaction, such information should include the following:

i) Initial price, including all fixed compulsory charges collected and/or imposed by the business;

ii) Information on the existence of variable compulsory and optional charges collected and/or imposed by the business when they become known by the business and before consumers confirm the transaction;

iii) Notice of the existence of other routinely applicable costs to the consumer that are collected and/or imposed by third parties;

iv) Terms, conditions, and methods of payment, including contract duration, recurring charges, such as automatic repeat purchases and subscription renewals, and ways to opt out from such automatic arrangements;

v) Terms of delivery or performance;

vi) Details of and conditions related to withdrawal, termination or cancellation, aftersales service, return, exchange, refunds, warranties and guarantees;

vii) Privacy policy; and

viii) Information on available dispute resolution and redress options.

53. To achieve the purpose of this Recommendation, governments should, in cooperation with stakeholders:

i) Work towards improving the evidence base for e-commerce policy making through:

- The collection and analysis of consumer complaints, surveys and other trend data, and

- Empirical research based on the insights gained from information and behavioural economics; 
Some of the provisions relating to fair business, advertising and marketing practices are also related to online disclosure; the most relevant provisions are replicated below.

\section{B. Fair Business, Advertising and Marketing Practices}

4. Businesses should not make any representation, or omission, or engage in any practice that is likely to be deceptive, misleading, fraudulent or unfair. This includes the general impression likely conveyed to consumers by the representation or practice as well as implied factual misrepresentations conveyed through features such as the good or the service's name, words, pictures, audio and/or video and the use of disclaimers that are hidden, hard to notice or to understand.

5. Businesses should not misrepresent or hide terms and conditions that are likely to affect a consumer's decision regarding a transaction.

16. Businesses should ensure that advertised prices do not misrepresent or hide the total cost of a good or a service. 


\section{Annex B. Consumer testing}

As noted in Chapter 4, the type and form of information that consumers need when shopping online is likely to vary between markets. In addition, what works for consumers in one market may not work in another. For this reason, governments and businesses should consider undertaking consumer testing of the effectiveness of various forms of online disclosures. As noted by Sunstein $\left(2011\right.$, p. $\left.1371_{[72]}\right)$ :

To the extent possible, agencies should study in advance the actual effects of alternative disclosure designs to ensure that information is properly presented and will actually inform consumers.

This is especially important in markets that are more susceptible to consumer detriment. This could include markets where:

- consumers are locked-in to their decision or there are other barriers to consumer switching (for example, a lack of effective competition)

- the decision represents a significant commitment for the consumer (monetary or otherwise)

- the decision is not routine for the consumer

- the decision involves a level of complexity.

It is also important that consumer testing is undertaken where policymakers are considering introducing mandatory disclosure requirements.

In practice, there are a number of examples where academics, governments or businesses have tested information disclosures on consumers. Examples for payday loans, pensions, health insurance, pharmaceutical labels, and mortgage disclosures are briefly discussed in Box B.1.

The rest of the annex provides some broad guidance on how to undertake a behavioural experiment to test the effectiveness of online information disclosures. It is not intended to be an exhaustive discussion of the issues but merely a high-level summary of some of the key considerations.

\section{Problem identification}

The first step involves identification of the problem. This involves asking:

- What is the consumer issue and why is it occurring?

- What is the behavioural element?

- Is it a problem of not enough information; too much information; information being provided at the wrong time or in the wrong form; consumer biases influencing decisions; or do consumers not understand the information?

- If consumers don't understand the information, why is this?

- Can improved disclosures help?

The specific policy issue and its behavioural aspects should be identified and defined as tightly as possible. Focus groups (and potentially initial testing) could be used to determine the extent of the problem and to act as a baseline against which to measure the success of any change. 


\section{Box B.1. Examples of consumer testing of disclosures}

The EC $\left(2016_{[52]}\right)$ commissioned work to test a number of methods for increasing readership of terms and conditions. Successful methods included shortening and simplifying terms and conditions, forced consumer exposure to terms and conditions, reading time prompts, and use of trust marks/seals (see Section 4.2).

Bertrand and Morse $\left(2011_{[165]}\right)$ looked at the effect of information disclosure on consumers' willingness to take out payday loans. They found that information disclosures that respond to cognitive biases can reduce intentions to take out loans by $11 \%$. The most effective disclosures made consumers consider the long term costs of loans, both in total and in comparison to other forms of lending.

The FTC undertook a study to improve mortgage disclosures for consumers (Lacko and Pappalardo, $\left.2007_{[166]}\right)$. The study involved 36 in-depth interviews with recent mortgage customers, and quantitative consumer testing of over 800 mortgage customers. Prototype disclosures were developed to test the potential for improved understanding of mortgage costs through better disclosures.

The Association of Superannuation Funds of Australia funded a study of consumer comprehension of a product disclosure statement for superannuation (i.e. retirement savings) products (Productivity Commission, 2008 ${ }_{[29]}$ ). Initially, only $10 \%$ of consumers correctly answered $90 \%$ of the questions. Interviews were used to identify reasons for mistakes and to re-design the statement. Changes included clearly explaining terms, using worked examples when relying on percentages, using "signposts", and including a checklist. With the new statement, $40 \%$ of consumers correctly answered $90 \%$ of the questions.

In the US, similar consumer testing was undertaken to develop a short, easy-tounderstand "Summary of Benefits and Coverage" and glossary to assist consumers in understanding and choosing between health insurance options (The Centre for Consumer Information \& Insurance Oversight (U.S), $\left.2012_{[167]}\right)$.

GlaxoSmithKline, a pharmaceuticals company, funded a study to test and improve label comprehension for Panadol - a painkiller sold in Australia (Productivity Commission, $\left.2008_{[29]}\right)$. Redesigning the label improved comprehension and understanding from 72 per cent to 92 per cent. Changes included better sequencing, reduced text length and increasing spacing, better differentiating between different types of information, and removing unnecessary information.

Other examples of experiments relating to information disclosures are discussed in "Use of Behavioural Insights in Consumer Policy" (OECD, 2017 $[2]$ ), and more general examples are in the OECD's report on "Behavioural Insights and Public Policy: Lessons from Around the World" (OECD, 2017 $\left.{ }_{[9]}\right)$.

\section{Developing options for improving disclosures}

The second step involves identifying ways to improve disclosures, based on the policy issue identified in the first step. There are a number of ways in which disclosures could potentially be improved including by: 
- simplifying text, including by removing technical language

- reducing the amount of text, potentially through layering

- ensuring key points are clear and salient

- using effective signposting

- using appropriate text size, colour and font (with consideration of the device on which the disclosures will appear)

- using images, audio or video, as appropriate

- changing the timing of the disclosure, and/or providing the relevant information at various decision points

- personalising disclosures.

Areas to target should be informed by the initial focus group or testing or relevant literature on the topic. From this, a number of options should be developed for testing.

The number of different interventions to be included for testing should be minimised as each intervention exponentially increases the number of conditions to be included (Van Bavel, Rodríguez-Priego and Maghiros, 2015 [168] $)$. For example, if testing consumer comprehension of a label, label colour, text size and logo placement might be relevant factors. However, this alone could involve at least nine test conditions so as to pick up differences between individual effects and interactions between effects:

- To compare two colours would require three conditions (e.g. blue, green and the control condition).

- To then test font size would require five conditions (e.g. blue-small, blue-big, green-small, green-big, and the control condition).

- To test placement would require nine conditions to account for all permutations (e.g. blue-small-high, blue-small-low, blue-big-high, blue-big-low, green-smallhigh, green-small-low, green-big-high, green-big-low, and the control condition).

The problem with including too many conditions is that it quickly expands the required sample size, which also increases the cost of the experiment. Further, increasing the number of conditions quickly increases complexity, making it harder to understand and clearly identify the potential policy interventions.

\section{Testing options}

Third, the options should be tested. This could be done in a laboratory setting, online, through a randomised control trial, or in the field. See OECD $\left(2017_{[2]}\right)$ for more on these types of testing. Alternatively, a combination of methods could be used as recommended by Garrison et al. $\left(2012_{[143]}\right)$.

Testing the effectiveness of certain types of interventions could be done in a number of ways:

- The experiment could look at the effect of various disclosures on actual consumer behaviour (for example, see Bertrand and Morse $\left(2011_{[165]}\right)$ ). That is, consumers could be shown different disclosures and certain behaviours could subsequently be monitored to assess whether changes in behaviour were correlated with exposure to different forms of disclosure. This approach is more likely to work in a randomised control trial, a laboratory experiment, or an online experiment.

- A "natural experiment" could shed light on the effectiveness of various forms of disclosures (for example, see FCA $\left(2015_{[154]}\right)$ ). That is, historic data could be used to test the actual effect of different forms of disclosures on consumers. For 
example, if a new disclosure was introduced, data on behaviour could be analysed before and after the introduction to see whether it resulted in a change in behaviour.

- The experiments could involve a specific activity (for example, a purchase activity) with an objectively "correct" outcome and then the various interventions could be tested to see how often they resulted in consumers arriving at the correct outcome, and/or how long it took consumers to arrive at that outcome (for example, see Esposito et al. $\left.\left(2017_{[146]}\right)\right)$. Such an approach would lend itself to a laboratory or online experiment.

- Consumers could be tested on their comprehension of the disclosure (for example, see Lacko and Pappalardo $\left.\left(2007_{[166]}\right)\right)$.

- Another option would be to ask consumers their views on the various interventions/presentations (for example, see EC $\left(2016_{[52]}\right)$ ).

Once the most effective disclosures have been identified through the testing, the benefits from the intervention should be compared with its costs. Only if the benefits of intervention outweigh the costs should the intervention be implemented.

\section{Other factors to consider}

When undertaking consumer testing, the sample size should be sufficiently large and representative of the underlying population (Van Bavel, Rodríguez-Priego and Maghiros, $\left.2015_{[168]}\right)$.

Another thing to consider is to what extent the results are generalizable since this is not necessarily the case with behavioural experiments. For example, consumers in one jurisdiction may differ markedly from consumers in another jurisdiction in terms of what interventions they find most useful. This could be because of differences in underlying socio-economic characteristics (which may be able to be tested and controlled for), or more fundamental cultural differences such as "aversion to risk, inter-temporal preferences, importance of altruism and other behavioural traits" (Helleringer and Sibony, 2016, p. $\left.35_{[60]}\right)$. For this reason, caution needs to be applied before assuming that the results of one experiment are generalizable to other populations or circumstances. Piloting certain interventions on a larger scale after testing can be a way of progressively introducing changes. Policy interventions should then be evaluated after a period of implementation to assess impact and effectiveness.

For more guidance on undertaking behavioural experiments in developing consumer policy, see the OECD's report "Use of Behavioural Insights in Consumer Policy" (OECD, 2017 $[2])$. 


\section{References}

ACCC (2015), Court finds that Jetstar and Virgin Australia engaged in misleading 'drip pricing' practices, https://www.accc.gov.au/media-release/court-finds-that-jetstar-and-virgin-australiaengaged-in-misleading-drip-pricing-practices (accessed on 07 August 2017).

ACCC (2016), Charles Tyrwhitt pays penalty for an alleged false or misleading 'was/now' pricing representation, https://www.accc.gov.au/media-release/charles-tyrwhitt-pays-penaltyfor-an-alleged-false-or-misleading-\%E2\%80\%98was-now\%E2\%80\%99-pricingrepresentation (accessed on 10 August 2017).

ACCC (2017), Advertising and selling guide - Component pricing, https://www.accc.gov.au/publications/advertising-selling/advertising-and-sellingguide/pricing/component-pricing (accessed on 04 August 2017).

ACCC (2017), Advertising and selling guide - Two-price comparison advertising, https://www.accc.gov.au/publications/advertising-selling/advertising-and-sellingguide/pricing/two-price-comparison-advertising (accessed on 10 August 2017).

Ahmetoglu, G. et al. (2010), Pricing Practices: Their Effects on Consumer Behaviour and Welfare, Prepared for the Office of Fair Trading, http://webarchive.nationalarchives.gov.uk/20140402172955/http://oft.gov.uk/shared oft/busin ess_leaflets/659703/Advertising-of-prices/Pricing-Practices.pdf (accessed on 02 August 2017).

Ahmetoglu, G., A. Furnham and P. Fagan (2014), "Pricing practices: A critical review of their effects on consumer perceptions and behaviour", Journal of Retailing and Consumer Services, http://dx.doi.org/10.1016/j.jretconser.2014.04.013.

Akerlof, G. (1970), "The Market for "Lemons": Quality Uncertainty and the Market Mechanism", The Quarterly Journal of Economics, Vol. 84/3, http://links.jstor.org/sici?sici=00335533\%28197008\%2984\%3A3\%3C488\%3ATMF\%22QU\%3E2.0.CO\%3B2-6 (accessed on 06 July 2017), pp. 488-500.

Allcott, H. (2011), "Social norms and energy conservation", Journal of Public Economics, Vol. 95, pp. 1082-1095, http://dx.doi.org/10.1016/j.jpubeco.2011.03.003.

Almuhimedi, H. et al. (2014), Your Location has been Shared 5,398 Times!: A Field Study on Mobile App Privacy Nudging, http://dx.doi.org/10.1145/2702123.2702210.

Aral, S. (2013), The Problem With Online Ratings, https://sloanreview.mit.edu/article/theproblem-with-online-ratings-2/.

Australian Government (2006), The Australian Guidelines for Electronic Commerce, https://archive.treasury.gov.au/documents/1083/PDF/australian_guidelines_for_electronic_co mmerce.pdf (accessed on 24 August 2017). 
Australian Government (2017), Energy Made Easy, https://www.energymadeeasy.gov.au/ (accessed on 24 August 2017).

Ayres, I. and A. Schwartz (2014), "The No-Reading Problem in Contract Law”, Faculty Scholarship Series, No. Paper 4872, Yale Law School, http://digitalcommons.law.yale.edu/fss_papers (accessed on 28 August 2017).

Bakos, Y., F. Marotta-Wurgler and D. Trossen (2014), "Does Anyone Read the Fine Print? Consumer Attention to Standard-Form Contracts", The Journal of Legal Studies, Vol. 43/1, pp. 1-35, http://dx.doi.org/10.1086/674424.

Balebako, R. et al. (2017), "Nudging users towards privacy on mobile devices", ACM Computing Surveys (CSUR), Vol. 50/3, https://www.andrew.cmu.edu/user/pgl/paper6.pdf, http://dx.doi.org/10.1145/3054926.

Bar-Gill, O. (2012), Seduction by contract: law, economics, and psychology in consumer markets, Oxford University Press.

Baye, M. (2012), What do "Off the Shelf" Theory Models Say About Drip Pricing?, Federal Trade Commission (US), https://www.ftc.gov/sites/default/files/documents/public events/economics-drippricing/mbaye.pdf (accessed on 04 August 2017).

Beales, H., R. Craswell and S. Salop (1981), “The Efficient Regulation of Consumer Information", The Journal of Law \& Economics, Vol. 24/3, pp. 491-539, http://dx.doi.org/10.2307/725275.

Becher, S. and T. Zarsky (2008), "E-Contract Doctrine 2.0: Standard Form Contracting in the Age of Online User Participation", Michigan Telecommunications and Technology Law Review, Vol. 14/2, http://repository.law.umich.edu/mttlr (accessed on 18 August 2017), pp. 303-366.

Bei, L., E. Chen and R. Widdows (2004), “Consumers' Online Information Search Behavior and the Phenomenon of Search vs. Experience Products", Journal of Family and Economic Issues, Vol. 25/4, https://link.springer.com/content/pdf/10.1007\%2Fs10834-004-5490-0.pdf (accessed on 01 March 2018), pp. 449-467.

Benartzi, S. and J. Lehrer (2017), The smarter screen: surprising ways to influence and improve online behavior, Penguin, New York.

Ben-Shahar, O. (2008), "The Myth of the 'Opportunity to Read' in Contract Law", Law \& Economics Working Papers, http://chicagounbound.uchicago.edu/law and economics/549 (accessed on 06 July 2017).

Ben-Shahar, O. (2008), "The Myth of the 'Opportunity to Read' in Contract Law", Law \& Economics Working Papers, http://chicagounbound.uchicago.edu/law and economics/549 (accessed on 06 July 2017).

Bertrand, M. and A. Morse (2011), "Information Disclosure, Cognitive Biases, and Payday Borrowing", The Journal of Finance, Vol. 66/6, http://www.jstor.org/stable/41305179 (accessed on 22 August 2017), pp. 1865-1893.

Bikhchandi, S., D. Hirshleifer and I. Welch (1998), "Learning from the Behavior of Others: Conformity, Fads, and Informational Cascades", No. 98010, University of Michigan Business School, https://deepblue.lib.umich.edu/bitstream/handle/2027.42/35413/b2013472.0001.001.pdf?seque $\underline{\text { nce }=2}$ (accessed on 03 August 2017). 
CAA (2017), Report on Reservation Representation (Overview), http://www.caa.go.jp/en/pdf/en_171213_0001.pdf (accessed on 14 December 2017).

Campbell, M., G. Mohr and P. Verlegh (2013), "Can disclosures lead consumers to resist covert persuasion? The important roles of disclosure timing and type of response", Journal of Consumer Psychology, Vol. 23/4, pp. 483-495, http://dx.doi.org/10.1016/j.jcps.2012.10.012.

Carroll, G. et al. (2009), "Optimal Defaults and Active Decisions", Quarterly Journal of Economics, Vol. 124/4, pp. 1639-1674, http://dx.doi.org/10.1162/qjec.2009.124.4.1639.

Choe, E. et al. (2013), Nudging People Away From Privacy-Invasive Mobile Apps Through Visual Framing, http://dx.doi.org/10.1007/978-3-642-40477-1_5.

Cialdini, R. (2006), Influence: The Psychology of Persuasion, Revised Edition, Harper Business.

Citizens Advice (2016), Against the clock: Why more time isn't the answer for consumers, https://www.citizensadvice.org.uk/Global/CitizensAdvice/Consumer\%20publications/Finalrep ort-Againsttheclock.pdf (accessed on 01 August 2017).

CMA (2012), Airlines: payment card surcharges investigation, https://www.gov.uk/cmacases/airlines-payment-card-surcharges-investigation (accessed on 01 August 2017).

CMA (2015), Unfair contract terms guidance Guidance on the unfair terms provisions in the Consumer Rights Act 2015, https://www.gov.uk/government/uploads/system/uploads/attachment_data/file/450440/Unfair Terms Main Guidance.pdf (accessed on 28 February 2018).

Competition Bureau (Canada) (2017), Price-related representations, http://www.competitionbureau.gc.ca/eic/site/cb-bc.nsf/eng/00522.html (accessed on 29 November 2017).

Competition Policy International (2017), Canada: \$1.25 million settlement in car rental drip pricing case, https://www.competitionpolicyinternational.com/canada-1-25-millionsettlement-in-car-rental-drip-pricing-case/ (accessed on 04 August 2017).

Darby, M. et al. (1973), "Free Competition and the Optimal Amount of Fraud", The Journal of Law \& Economics, Vol. 16/1, http://www.jstor.org/stable/724826 (accessed on 06 July 2017), pp. 67-88.

Darke, P., A. Chattopadhyay and L. Ashworth (2006), "The Importance and Functional Significance of Affective Cues in Consumer Choice", Journal of Consumer Research, Vol. 33/33, pp. 322-328, http://dx.doi.org/10.1086/508437.

Deltas, G. and Z. Li (2017), Free Riding on the Search of Others: Information Externalities in the Mortgage Industry, http://faculty.las.illinois.edu/deltas/Deltas_Li_IIOC_2017.pdf (accessed on 06 July 2017).

Department for Business Innovation \& Skills (United Kingdom) (2016), Terms and Conditions and Consumer Protection Fining Powers: Call For Evidence, https://www.gov.uk/government/uploads/system/uploads/attachment_data/file/504063/bis-1667-terms-and-conditions-call-for-evidence.pdf (accessed on 18 August 2017).

Dewally, M. and L. Ederington (2006), "Reputation, Certification, Warranties, and Information as Remedies for Seller-Buyer Information Asymmetries: Lessons from the Online Comic Book Market", The Journal of Business, Vol. 79/2, pp. 693-729, http://dx.doi.org/10.1086/499169. 
Dimoka, A., Y. Hong and P. Pavlou (2012), "On Product Uncertainty in Online Markets: Theory and Evidence", MIS Quarterly, Vol. 36/2, https://eds-b-ebscohostcom.ezp.lib.unimelb.edu.au/eds/pdfviewer/pdfviewer?vid=1\&sid=0742eb26-820b-489b-9e402a492f7eca74\%40sessionmgr102 (accessed on 01 March 2018), pp. 395-426.

Duan, W., B. Gu and A. Whinston (2009), "Informational Cascades and Software Adoption on the Internet: An Empirical Investigation", MIS Quarterly, Vol. 3/1, http://www.jstor.org/stable/pdf/20650277.pdf?refreqid=excelsior\%3A3619bd53a7130c1e64d9 5f98ad7fafd4 (accessed on 03 August 2017), pp. 23-48.

Ellison, G. and S. Fischer Ellison (2009), "Search, Obfuscation, and Price Elasticities on the Internet”, Econometrica, Vol. 77/2, pp. 427-452, http://dx.doi.org/10.3982/ECTA5708.

Esposito, G. et al. (2017), "Nudging to prevent the purchase of incompatible digital products online: An experimental study", PLoS ONE, Vol. 12/3, http://dx.doi.org/10.1371/journal.pone.0173333.

EULAlyzer (2017), EULAlyzer, http://www.brightfort.com/eulalyzer.html\#Overview (accessed on 18 August 2017).

European Commission (2016), Consumer vulnerability across key markets in the European Union, http://ec.europa.eu/consumers/consumer evidence/market studies/docs/vulnerable consumers _approved_27_01_2016_en.pdf (accessed on 28 November 2017).

European Commission (2016), The Black List: banned commercial practices, http://ec.europa.eu/justice/consumer-marketing/unfair-trade/unfair-practices/is-itfair/blacklist/index_en.htm (accessed on 01 September 2017).

European Commission (2016), Study on consumers' attitudes towards Terms and Conditions, http://ec.europa.eu/consumers/consumer_evidence/behavioural_research/docs/terms_and_cond itions_final_report_en.pdf (accessed on 06 July 2017).

European Commission (2017), Booking your holidays online: Commission and consumer protection authorities act on misleading travel booking websites, http://europa.eu/rapid/pressrelease_IP-17-844_en.htm (accessed on 07 August 2017).

European Union (2011), Directive 2011/83/EU of the European Parliament and of the Council on Consumer Rights, Official Journal of the European Union, http://eur-lex.europa.eu/legalcontent/EN/TXT/PDF/?uri=CELEX:32011L0083\&rid=1 (accessed on 01 August 2017).

Facebook IQ (2017), Unfiltered: Looking at Instagrammers Through a Biometric Lens, https://www.facebook.com/iq/articles/unfiltered-looking-at-instagrammers-through-abiometric-lens?ref=wpinsights rd (accessed on 01 February 2018).

Facebook (2015), How the Brain Processes Mobile and TV Ads, https://fbinsights.files.wordpress.com/2015/06/facebookiq_neuro_whitepaper_june2015.pdf (accessed on 01 February 2018).

Faure, M. and H. Luth (2011), "Behavioural Economics in Unfair Contract Terms Cautions and Considerations", Journal of Consumer Policy, Vol. 34, pp. 337-358, http://dx.doi.org/10.1007/s10603-011-9162-9.

FCA (2015), Message received? The impact of annual summaries, text alerts and mobile apps on consumer banking behaviour, https://www.fca.org.uk/publication/occasionalpapers/occasional-paper-10.pdf (accessed on 05 September 2017). 
FTC (2009), Sears Settles FTC Charges Regarding Tracking Software, https://www.ftc.gov/newsevents/press-releases/2009/06/sears-settles-ftc-charges-regarding-tracking-software (accessed on 04 September 2017).

FTC (2009), Negative Options, https://www.ftc.gov/sites/default/files/documents/reports/negativeoptions-federal-trade-commission-workshop-analyzing-negative-option-marketing-reportstaff/p064202negativeoptionreport.pdf (accessed on 08 August 2017).

FTC (2012), FTC Warns Hotel Operators that Price Quotes that Exclude 'Resort Fees' and Other Mandatory Surcharges May Be Deceptive, https://www.ftc.gov/news-events/pressreleases/2012/11/ftc-warns-hotel-operators-price-quotes-exclude-resort-fees-other (accessed on 07 August 2017).

FTC (2013), FTC Consumer Protection Staff Updates Agency's Guidance to Search Engine Industry on the Need to Distinguish Between Advertisements and Search Results, https://www.ftc.gov/news-events/press-releases/2013/06/ftc-consumer-protection-staff-updatesagencys-guidance-search (accessed on 18 December 2017).

FTC (2015), Native Advertising: A Guide for Businesses, https://www.ftc.gov/tips-advice/businesscenter/guidance/native-advertising-guide-businesses (accessed on 18 December 2017).

FTC (2016), Putting Disclosures to the Test Workshop: Staff Summary, https://www.ftc.gov/system/files/documents/reports/putting-disclosures-test/disclosuresworkshop-staff-summary-update.pdf (accessed on 02 August 2017).

FTC (2017), Blurred Lines: An Exploration of Consumers' Advertising Recognition in the Contexts of Search Engines and Native Advertising, FTC Staff Report, Washington, https://www.ftc.gov/system/files/documents/reports/blurred-lines-exploration-consumersadvertising-recognition-contexts-search-enginesnative/p164504_ftc_staff_report_re_digital_advertising_and_appendices.pdf (accessed on 18 December 2017).

Gabaix, X. and D. Laibson (2006), "Shrouded Attributes, Consumer Myopia, and Information Suppression in Competitive Markets", The Quarterly Journal of Economics, Vol. June, http://pages.stern.nyu.edu/ xgabaix/papers/shrouded.pdf (accessed on 04 August 2017), pp. 505-540.

Gal, M. and N. Elkin-Koren (2017), “Algorithmic Consumers”, Harvard Journal of Law \& Technology, Vol. 30/2, http://jolt.law.harvard.edu/assets/articlePDFs/v30/30HarvJLTech309.pdf, pp. 309-353.

Garrison, L. et al. (2012), "Designing Evidence-based Disclosures: A Case Study of Financial Privacy Notices", Journal of Consumer Affairs, Vol. 46/2, pp. 204-234, http://dx.doi.org/10.1111/j.1745-6606.2012.01226.x.

Gill Wales Research (2014), Consumers' engagement with markets and the implications for their use of time, http://www.gillwales.co.uk (accessed on 19 July 2017).

Gindin, S. (2009), "Nobody Reads Your Privacy Policy or Online Contract? Lessons Learned and Questions Raised by the FTC's Action Against Sears", Northwestern Journal of Technology and Intellectual Property, Vol. 8/1, http://scholarlycommons.law.northwestern.edu/njtip/vol8/iss1/1 (accessed on 30 August 2017), pp. 1-37.

Goldstein, D. et al. (2008), "Nudge Your Customers Toward Better Choices", Harvard Business Review, Vol. December, https://hbr.org/2008/12/nudge-your-customers-toward-better-choices (accessed on 08 August 2017). 
Government of Canada (2013), Canadians Have Access to All-Inclusive Air Prices as Airlines

Transition to New Advertising Requirements,

https://www.canada.ca/en/news/archive/2013/03/canadians-have-access-all-inclusive-air-pricesairlines-transition-new-advertising-requirements.html (accessed on 28 November 2017).

Greenberg, A. (2018), Polisis AI Reads Privacy Policies So You Don't Have To, https://www.wired.com/story/polisis-ai-reads-privacy-policies-so-you-dont-have-to/ (accessed on 12 February 2018), p. 9.

Greenleaf, E. et al. (2016), "The price does not include additional taxes, fees, and surcharges: A review of research on partitioned pricing", Journal of Consumer Psychology, Vol. 24/1, http://ac.els-cdn.com/S105774081500042X/1-s2.0-S105774081500042Xmain.pdf? tid=68108912-8bdb-11e7-bee500000aacb362\&acdnat=1503916192_38610acf699a9b4a4e90c8fd71b7b425 (accessed on 28 August 2017), pp. 105-124.

Grubb, M. (2009), "Selling to Overconfident Consumers", American Economic Review, Vol. 99/995, http://www.jstor.org/stable/25592536 (accessed on 03 August 2017), pp. 17701807.

Grubb, M. (2015), "Overconfident Consumers in the Marketplace", The Journal of Economic Perspectives Journal of Economic Perspectives, Vol. 29/4, http://www.jstor.org/stable/43611009 (accessed on 03 August 2017), pp. 9-35.

Grundmann, S., W. Kerber and S. Weatherill (eds.) (2001), Party Autonomy and the Role of Information in the Internal Market, De Gruyter, Berlin, http://dx.doi.org/10.1515/9783110873030.

Hargittai, E. and S. Shafer (2006), "Differences in Actual and Perceived Online Skills: The Role of Gender", Social Sciences Quarterly, Vol. 87/2, http://www.eszter.com/research/pubs/hargittaishafer-ssq06.pdf, pp. 432-448.

Heidhues, P., B. Ko and T. Murooka (2016), "Exploitative Innovation”, American Economic Journal: Microeconomics, Vol. 8/1, pp. 1-23, http://dx.doi.org/10.1257/mic.20140138.

Helberger, N. (2013), Form matters: informing consumers effectively, Institute for Information Law, University of Amsterdam, https://www.ivir.nl/publicaties/download/Form matters.pdf (accessed on 30 August 2017).

Helleringer, G. and A. Sibony (2016), "European Consumer Protection Through the Behavioral Glass", Columbia Journal of European Law, Vol. 23/3.

Hern, A. (2015), "I read all the small print on the internet and it made me want to die", The Guardian, https://www.theguardian.com/technology/2015/jun/15/i-read-all-the-small-print-onthe-internet (accessed on 06 July 2017).

Hernandez, M. et al. (2017), Applying Behavioral Insights to Improve Tax Collection: Experimental Evidence from Poland, World Bank, Washington, D.C., https://openknowledge.worldbank.org/bitstream/handle/10986/27528/116046-WP-TaxCollection-PUBLIC.pdf?sequence $=1 \&$ isAllowed $=\mathrm{y}$ (accessed on 25 August 2017).

Hillman, R. (2005), On-line Consumer Standard-Form Contracting Practices: A Survey and Discussion of Legal Implications, http://scholarship.law.cornell.edu/lsrp papers (accessed on 06 July 2017). 
Hogarth, J. and E. Merry (2011), Designing Disclosures to Inform Consumer Financial

Decisionmaking: Lessons Learned from Consumer Testing the Role of Financial Product

Disclosures in Consumer Protection,

https://www.federalreserve.gov/pubs/bulletin/2011/pdf/designingdisclosures2011.pdf (accessed on 29 September 2017).

Howells, G. (2005), "The Potential and Limits of Consumer Empowerment by Information", Journal of Law and Society, Vol. 32/3, pp. 263-323, http://dx.doi.org/10.1111/j.14676478.2005.00328.x.

Ipsos MORI (2008), A new breed of shoppers - are UK retailers ready?, https://www.ipsos.com/sites/default/files/publication/1970-

01/Marketing Retail A\%20new\%20breed\%20of\%20shoppers Sep08.pdf (accessed on 01 August 2017).

Johnson, E. et al. (1993), "Framing, Probability Distortions, and Insurance Decisions", Journal of Risk and Uncertainty, https://www8.gsb.columbia.edu/decisionsciences/sites/decisionsciences/files/files/Framing_Prob ability_Distortions-3.pdf (accessed on 01 August 2017), pp. 35-51.

Johnson, E. and D. Goldstein (2004), "Defaults and Donation Decisions", Transplantation, Vol. 78, pp. 1713-1716, http://dx.doi.org/10.1097/01.TP.0000149788.10382.B2.

Kahneman, D., J. Knetsch and R. Thaler (1991), “Anomalies: The Endowment Effect, Loss Aversion, and Status Quo Bias", The Journal of Economic Perspectives, Vol. 5/1, https://www.princeton.edu/ kahneman/docs/Publications/Anomalies_DK_JLK_RHT_1991.pdf (accessed on 01 August 2017), pp. 193-206.

Kahneman, D., D. Lovallo and O. Sibony (2011), "Before You Make That Big Decision...", Harvard Business Review, Vol. June, https://www.aub.edu.lb/units/ehmu/Documents/beforeyou-make-that-big-decision.pdf (accessed on 03 August 2017), pp. 51-60.

King, S. and R. Smith (2010), "The shaky economic foundations of consumer protection policy and law", Competition \& Consumer Law Journal, Vol. 18/1, http://consumerlaw.gov.au/files/2015/09/Companion to OECD Toolkit.rtf, pp. 71-88.

Kolodko, J., D. Read and U. Taj (2016), Using Behavioural Insights to Reduce Littering in the UK, Clean Up Britain, Warwick Business School, http://www.nudgeathon.com/wpcontent/uploads/2016/01/CLUB-REPORT.pdf (accessed on 25 August 2017).

Kovač, M. and A. Vandenberghe (2015), "Regulation of Automatic Renewal Clauses: A Behavioural Law and Economics Approach", Journal of Consumer Policy, Vol. 38, pp. 287313, http://dx.doi.org/10.1007/s10603-015-9286-4.

Kristensen, H. and T. Gärling (2000), "Anchoring Induced Biases in Consumer Price Negotiations", Journal of Consumer Policy, Vol. 23, https://link.springer.com/content/pdf/10.1023\%2FA\%3A1007280722313.pdf (accessed on 08 August 2017), pp. 445-460.

Lacko, J. and J. Pappalardo (2004), The Effect of Mortgage Broker Compensation Disclosures on Consumers and Competition: A Controlled Experiment, Federal Trade Commission (U.S), http://citeseerx.ist.psu.edu/viewdoc/download?doi=10.1.1.167.5067\&rep=rep1\&type=pdf (accessed on 21 August 2017). 
Lacko, J. and J. Pappalardo (2007), Improving Consumer Mortgage Disclosures, Federal Trade Commission, https://www.ftc.gov/sites/default/files/documents/reports/improving-consumermortgage-disclosures-empirical-assessment-current-and-prototype-disclosureforms/p025505mortgagedisclosurereport.pdf (accessed on 21 August 2017).

Laibson, D. (2012), Drip pricing: A behavioral economics perspective, Federal Trade Commission (US), https://www.ftc.gov/sites/default/files/documents/public_events/economics-drippricing/dlaibson.pdf (accessed on 04 August 2017).

Lee, B. and W. Lee (2004), "The Effect of Information Overload on Consumer Choice Quality in an On-Line Environment", Psychology \& Marketing, Vol. 21/3, pp. 159-183, http://dx.doi.org/10.1002/mar.20000.

Leenheer, J. et al. (2014), Study on the effects on consumer behaviour of online sustainability information displays Internal identification, European Commission, http://dx.doi.org/10.2759/52063.

Levav, J. et al. (2010), "Order in Product Customization Decisions: Evidence from Field Experiments", Journal of Political Economy, Vol. 118/2, http://citeseerx.ist.psu.edu/viewdoc/download?doi=10.1.1.457.7194\&rep=rep1\&type=pdf (accessed on 11 August 2017).

Li, N. and G. Kirkup (2007), "Gender and cultural differences in Internet use: A study of China and the UK", Computers \& Education, Vol. 48, pp. 301-317, http://dx.doi.org/10.1016/j.compedu.2005.01.007.

Lithuania, C. (2015), Electronic Trade Offers Mislead Consumers, https://kt.gov.lt/en/news/competition-council-electronic-trade-offers-mislead-consumers (accessed on 02 August 2017).

Lunn, P. (2014), Regulatory policy and behavioural economics, OECD.

Luth, H. (2010), Behavioural economics in consumer policy: the economic analysis of standard terms in consumer contracts revisited, Intersentia, http://intersentia.com/en/behaviouraleconomics-in-consumer-policy.html (accessed on 09 August 2017).

Marotta-Wurgler, F. (2009), "Are "Pay Now, Terms Later" Contracts Worse for Buyers? Evidence from Software License Agreements", The Journal of Legal Studies, Vol. 38/2, pp. 309-343, http://dx.doi.org/10.1086/596040.

Marotta-Wurgler, F. (2011), "Some Realities of Online Contracting”, Supreme Court Economic Review, Vol. 19/1, http://www.jstor.org/stable/pdf/10.1086/664560.pdf?refreqid=excelsior:7cca94d964ee86929a88 0cf5bc608388 (accessed on 21 August 2017), pp. 11-23.

Marotta-Wurgler, F. (2012), “Does Contract Disclosure Matter?”, Journal of Institutional and Theoretical Economics, Vol. 168/1, http://web.law.columbia.edu/sites/default/files/microsites/contract-economicorganization/files/Marotta-Wurgler\%20paper.pdf (accessed on 27 November 2017), pp. 94-119.

Marotta-Wurgler, F. and R. Taylor (2013), "Set in Stone? Change and Innovation in Consumer Standard Form Contracts", New York University Law Review, Vol. 88, http://www.nyulawreview.org/sites/default/files/pdf/NYULawReview-88-1-MarottaWurglerTaylor.pdf (accessed on 27 November 2017), pp. 240-285. 
McDonald, A. and L. Cranor (2008), The Cost of Reading Privacy Policies,

http://www.ibrarian.net/navon/paper/The_Cost_of_Reading_Privacy_Policies.pdf?paperid=1246 $\underline{1314}$.

McDonald, A. and T. Lowenthal (2013), "Nano-Notice: Privacy Disclosure at a Mobile Scale", Source: Journal of Information Policy, Vol. 3, pp. 331-354, http://dx.doi.org/10.5325/jinfopoli.3.2013.0331.

Micklitz, H., P. Pałka and Y. Panagis (2017), "The Empire Strikes Back: Digital Control of Unfair Terms of Online Services", Journal of Consumer Policy, Vol. 40/2, pp. 1-22, http://dx.doi.org/10.1007/s10603-017-9353-0.

Miller, G. (1956), “The Magical Number Seven, Plus or Minus Two: Some Limits on Our Capacity for Processing Information", Psychological Review, Vol. 101/2, http://www.psych.utoronto.ca/users/peterson/psy430s2001/Miller\%20GA\%20Magical\%20Seve n\%20Psych\%20Review\%201955.pdf (accessed on 06 July 2017), pp. 343-352.

Milton, L. (2017), More penalties for digital "drip pricing”, Competition Chronicle, http://www.competitionchronicle.com/2017/05/more-penalties-for-digital-drip-pricing/ (accessed on 04 August 2017).

Morwitz, V. and S. Santana (2012), How consumers react to partitioned and drip pricing: Evidence from the lab, Federal Trade Commission (US), https://www.ftc.gov/sites/default/files/documents/public_events/economics-drippricing/vmorwitz.pdf.

Muir, D., K. Seim and M. Vitorino (2013), Drip Pricing When Consumers Have Limited Foresight: Evidence from Driving School Fees, Federal Trade Commission (US), https://www.ftc.gov/sites/default/files/documents/public_events/Federal\%20Trade\%20Commiss ion\%20Microeconomics\%20Conference/seim.pdf (accessed on 04 August 2017).

Naru, F. and F. Cavassini (2017), "La monté en puissance des insights comportementaux dans les politiques publiques", in Guide de l'Économie Comportementale, Labrador and BVA, https://www.bva-group.com/news/guide-nudge-2017.

Naru, F. and F. Cavassini (2018), "The evolution of behavioral insights in public policy: towards the next frontier", Behavioural Science \& Policy, Vol. 4/1.

Nelson, P. (1970), "Information and Consumer Behavior", Journal of Political Economy, Vol. 78/2, https://www.jstor.org/stable/pdf/1830691.pdf?refreqid=excelsior\%3A894a52299f32d4616c147f 7 efd238b9f (accessed on 06 July 2017), pp. 311-329.

Nelson, P. (1974), “Advertising as Information”, Journal of Political Economy, Vol. 82/4, http://www.jstor.org/stable/1837143 (accessed on 07 July 2017), pp. 729-754.

New Zealand Commerce Commission (2015), Bait advertising, http://www.comcom.govt.nz/fairtrading/fair-trading-act-fact-sheets/bait-advertising/ (accessed on 01 September 2017).

Norwegian Consumer Council (2016), Forbrukerministeren på mølla - YouTube, https://www.youtube.com/watch?v=_TlTx0IyuPA\&index=10\&list=PLsFhKPMzAmIyYGnV5B n7IQWYY1F2CQ_gP (accessed on 04 August 2017).

OECD (1999), Guidelines for Consumer Protection in the Context of Electronic Commerce, http://www.oecd.org/sti/consumer/34023811.pdf (accessed on 24 August 2017).

OECD (2005), Enhancing Competition in Telecommunications: Protecting and Empowering Consumers, http://www.oecd.org/dataoecd/31/46/36581073.pdf. (accessed on 04 August 2017). 
OECD (2006), "Making Privacy Notices Simple: An OECD Report and Recommendations", OECD Digital Economy Papers, No. 120, OECD Publishing, Paris, http://dx.doi.org/10.1787/231428216052.

OECD (2006), "Making Privacy Notice Simple: An OECD Report and Recommendations: Annexes", http://www.oecd.org/officialdocuments/publicdisplaydocumentpdf/?doclanguage=en $\&$ cote $=\mathrm{dsti} /$ iccp/reg(2006)5/final/ann (accessed on 01 September 2017).

OECD (2007), "Report on Second Roundtable on Economics for Consumer Policy", OECD Digital Economy Papers, No. 132, OECD Publishing, Paris, http://dx.doi.org/10.1787/230744208356.

OECD (2010), Consumer policy toolkit, OECD Publishing, Paris, http://dx.doi.org/10.1787/9789264079663-en.

OECD (2011), Protecting and Empowering Consumers in the Purchase of Digital Content Products, http://dx.doi.org/10.1787/5k49czlc7wd3-en.

OECD (2012), Summary Record of the Discussion on Behavioural Economics, OECD, Paris, http://www.oecd.org/officialdocuments/publicdisplaydocumentpdf/?cote=DAF/COMP/M(2012) 2/ANN5/FINAL\&docLanguage=En (accessed on 04 August 2017).

OECD (2014), Consumer Policy Guidance on Mobile and Online Payments, http://dx.doi.org/10.1787/5jz432cl1ns7-en.

OECD (2016), OECD Recommendation of the Council on Consumer Protection in E-Commerce, OECD Publishing, Paris, http://dx.doi.org/10.1787/9789264255258-en.

OECD (2016), Protecting Consumers through Behavioural Insights: Regulating the Communications Market in Colombia, OECD Publishing, Paris, http://dx.doi.org/10.1787/9789264255463-en.

OECD (2017), "Use of Behavioural Insights in Consumer Policy", OECD Science, Technology and Industry Policy Papers, No. 36, OECD Publishing, Paris, http://dx.doi.org/10.1787/c2203c35en.

OECD (2017), "Trust in peer platform markets: Consumer survey findings", OECD Digital Economy Papers, No. 263, OECD Publishing, Paris, http://dx.doi.org/10.1787/1a893b58-en.

OECD (2017), Behavioural Insights and Public Policy: Lessons from Around the World, OECD Publishing, Paris, http://dx.doi.org/10.1787/9789264270480-en.

OFT (2007), Internet Shopping: An OFT Market Study, http://webarchive.nationalarchives.gov.uk/20140402163042/http://oft.gov.uk/OFTwork/markets -work/internet (accessed on 01 August 2017).

OFT (2008), Consumer Protection from Unfair Trading: Guidance on the Consumer Protection from Unfair Trading Regulations 2008, http://www.theswa.org.uk/docs/consumer-protection.pdf (accessed on 08 August 2017).

OFT (2010), Advertising of Prices, http://webarchive.nationalarchives.gov.uk/20140402173016/http://oft.gov.uk/shared oft/marketstudies/AoP/OFT1291.pdf (accessed on 02 August 2017).

OFT (2012), Drip pricing: UK experience, https://www.ftc.gov/sites/default/files/documents/public_events/economics-drippricing/afletcher.pdf (accessed on 01 August 2017). 
OFT (2014), Investigations into the use of misleading reference pricing by certain furniture and carpet businesses, http://webarchive.nationalarchives.gov.uk/20140402171217/http://oft.gov.uk/OFTwork/consum er-enforcement/consumer-enforcement-completed/furniture-carpet/ (accessed on 02 August 2017).

Ogus, A. (2004), Regulation: legal form and economic theory, Hart Publishing.

Oxera (2013), Behavioural economics and its impact on competition policy, http://www.oxera.com/Oxera/media/Oxera/downloads/Agenda/Behavioural-economics-and-itsimpact-on-competition-policy.pdf?ext=.pdf (accessed on 04 August 2017).

Parris, R. (2012), Online Terms and Conditions longer that Shakespeare plays - who reads them?, Which? Conversation, https://conversation.which.co.uk/technology/length-of-website-termsand-conditions/ (accessed on 06 July 2017).

Pitofsky, R., R. Shaheen and A. Mudge (2004), "Pricing Laws are No Bargain for Consumers", Antitrust, Vol. 18, https://files.arnoldporter.com/article-pricing_laws(7-04).pdf (accessed on 28 February 2018), pp. 62-65.

Porat, A. and L. Strahilevitz (2014), "Personalizing Default Rules and Disclosure with Big Data", Michigan Law Review, Vol. 112/8, http://repository.law.umich.edu/mlr (accessed on 24 August 2017), pp. 1417-1478.

Productivity Commission (2008), Review of Australia's Consumer Policy Framework, Productivity Commission, Canberra, http://www.pc.gov.au/inquiries/completed/consumer-policy/ (accessed on 06 July 2017).

Ramsay, I. (2012), Consumer Law and Policy: Text and Materials on Regulating Consumer Markets, Hart Publishing.

Rischkowsky, F. and T. Döring (2008), "Consumer Policy in a Market Economy: Considerations from the Perspective of the Economics of Information, the New Institutional Economics as well as Behavioural Economics", Journal of Consumer Policy, Vol. 31, pp. 285-313, http://dx.doi.org/10.1007/s10603-008-9076-3.

Salop, S. and J. Stiglitz (1977), "Bargains and Ripoffs: A Model of Monopolistically Competitive Price Dispersion", The Review of Economic Studies, Vol. 44/3, http://www.jstor.org/stable/2296903 (accessed on 07 July 2017), pp. 493-510.

Samuelson, W. and R. Zeckhauser (1988), "Status Quo Bias in Decision Making”, Joumal of Risk and Uncertainty, Vol. 1, https://sites.hks.harvard.edu/fs/rzeckhau/SQBDM.pdf, pp. 7-59.

Shahnazari, S. et al. (2016), "Promoting Healthy Eating Habits", MaRS Solutions Lab, Canada, https://www.marsdd.com/wp-content/uploads/2016/03/MSL ABI-Working-Paper.pdf (accessed on 25 August 2017).

Smithers, R. (2011), Terms and conditions: not reading the small print can mean big problems, The Guardian, https://www.theguardian.com/money/2011/may/11/terms-conditions-small-print-bigproblems (accessed on 19 July 2017).

Sousa Lourenço, J. et al. (2016), Behavioural Insights Applied to Policy: European Report 2016, European Commission, http://dx.doi.org/10.2760/903938.

Stark, D. and J. Choplin (2009), "A License to Deceive: Enforcing Contractual Myths Despite Consumer Psychological Realities", NYU Journal of Law \& Business, Vol. Spring, https://papers.ssrn.com/sol3/papers.cfm?abstract_id=1340166 (accessed on 06 July 2017). 
Stigler, G. (1961), "The Economics of Information”, The Journal of Political Economy, Vol. 69/3, http://home.uchicago.edu/ vlima/courses/econ200/spring01/stigler.pdf (accessed on 06 July 2017), pp. 213-225.

Stiglitz, J. (2000), "The Contributions of the Economics of Information to Twentieth Century Economics", The Quarterly Journal of Economics, Vol. 115/4, http://ricardo.ecn.wfu.edu/ cottrell/papers/stiglitz.pdf (accessed on 06 July 2017), pp. 14411478.

Sullivan, M. (2017), Economic Analysis of Hotel Resort Fees, Federal Trade Commission (US), https://www.ftc.gov/system/files/documents/reports/economic-analysis-hotel-resortfees/p115503 hotel resort fees economic issues paper.pdf (accessed on 01 August 2017).

Sunstein, C. (2011), "Empirically Informed Regulation", The University of Chicago Law Review, Vol. 78/4, http://chicagounbound.uchicago.edu/cgi/viewcontent.cgi?article=5551\&context=uclrev (accessed on 22 August 2017), pp. 1349-1429.

Sunstein, C. (2013), "Deciding by Default", University of Pennsylvania Law Review, Vol. 162/1, http://scholarship.law.upenn.edu/cgi/viewcontent.cgi?article=1000\&context=penn_law_review (accessed on 24 August 2017), pp. 1-57.

Sunstein, C. (2014), "Nudging: A Very Short Guide", Journal of Consumer Policy, Vol. 37, pp. 583-588, http://dx.doi.org/10.1007/s10603-014-9273-1.

Sunstein, C., L. Reisch and J. Rauber (2017), "Behavioral Insights All Over the World? Public Attitudes Toward Nudging in a Multi-Country Study", SSRN Electronic Journal, http://dx.doi.org/10.2139/ssrn.2921217.

Thaler, R. and C. Sunstein (2008), Nudge: improving decisions about health, wealth, and happiness, Penguin Books.

The Centre for Consumer Information \& Insurance Oversight (U.S) (2012), Providing Clear and Consistent Information to Consumers About Their Health Insurance Coverage, https://www.cms.gov/CCIIO/Resources/Fact-Sheets-and-FAQs/labels08172011a.html (accessed on 22 August 2017).

The Gallup Organisation (2013), Testing of a Standardised Information Notice for Consumers on the Common European Sales Law, European Commission, http://ec.europa.eu/justice/contract/files/common_sales_law/cesl_gallup_consortium_final_repo rt_en.pdf (accessed on 23 August 2017).

TNS (2012), Bank fees behaviour study, European Commission, http://ec.europa.eu/consumers/financial services/reference studies documents/docs/report 614 6 bankfees en.pdf (accessed on 23 August 2017).

Tversky, A. and D. Kahneman (1974), "Judgment under Uncertainty: Heuristics and Biases", Science, New Series, Vol. 185/4157, http://links.jstor.org/sici?sici=00368075\%2819740927\%293\%3A185\%3A4157\%3C1124\%3AJUUHAB\%3E2.0.CO\%3B2-M (accessed on 08 August 2017), pp. 1124-1131.

Tversky, A. and D. Kahneman (1981), "The Framing of Decisions and the Psychology of Choice", Science, New Series, Vol. 211/4481, http://links.jstor.org/sici?sici=00368075\%2819810130\%293\%3A211\%3A4481\%3C453\%3ATFODAT\%3E2.0.CO\%3B2-3 (accessed on 06 July 2017), pp. 453-458. 
Tversky, A. and D. Kahneman (1992), “Advances in Prospect Theory: Cumulative Representation of Uncertainty", Journal of Risk and Uncertainty, Vol. 5, https://link.springer.com/content/pdf/10.1007\%2FBF00122574.pdf (accessed on 08 August 2017), pp. 297-323.

Urbany, J., W. Bearden and D. Weilbaker (1988), "The Effect of Plausible and Exaggerated Reference Prices on Consumer Perceptions and Price Search", Journal of Consumer Research, Vol. 15/1, http://www.jstor.org/stable/2489175 (accessed on 08 August 2017), pp. 95-110.

uTerms (2017), uTerms, http://uterms.software/ (accessed on 18 August 2017).

Van Bavel, R., N. Rodríguez-Priego and I. Maghiros (2015), Seven Points to Remember when Conducting Behavioural Studies in Support of EU Policy-making, European Commission, Joint Research Centre, http://dx.doi.org/10.2791/743188.

Van Boom, W. (2011), "Price Intransparency, Consumer Decision Making and European Consumer Law", Journal of Consumer Policy, Vol. 34, pp. 359-376, http://dx.doi.org/10.1007/s10603-011-9163-8.

Van Deursen, A. and J. Van Dijk (2010), "Internet skills and the digital divide", New Media \& Society, Vol. 1/6, pp. 893-911, http://dx.doi.org/10.1177/1461444810386774.

Van Deursen, A., J. Van Dijk and O. Peters (2011), "Rethinking Internet skills: The contribution of gender, age, education, Internet experience, and hours online to medium- and content-related Internet skills", Poetics, Vol. 39, pp. 125-144, http://dx.doi.org/10.1016/j.poetic.2011.02.001.

Warren, E. (2008), "Making Credit Safer: The case for regulation", Harvard Magazine, Vol. MayJune, https://harvardmagazine.com/2008/05/making-credit-safer-html, p. 34.

Xia, L. and K. Monroe (2004), "Price Partitioning on the Internet", Journal of Interactive Marketing, Vol. 18/4, http://dx.doi.org/10.1002/dir.20017.

Zhenhui, J. and I. Benbasat (2007), "The Effects of Presentation Formats and Task Complexity on Online Consumers' Product Understanding”, MIS Quarterly, Vol. 31/3, http://www.jstor.org/stable/25148804 (accessed on 03 August 2017), pp. 475-500. 


\section{Notes}

1 See, for example, the "Report on the Second Roundtable on Economics for Consumer Policy" (OECD, 2007 $[172]$ ), the "Consumer Policy Toolkit" (OECD, 2010 $\left.0_{[4]}\right)$, the "Recommendation on Consumer Policy in E-Commerce" (OECD, 2016 $\left.6_{[3]}\right)$, and the "Use of Behavioural Insights in Consumer Policy" (OECD, 2017 $[2]$, which all discuss or refer to behavioural insights.

2 For more on mobile and online payments, see the "Consumer Policy Guidance on Mobile and Online Payments" (OECD, 2014 [85]).

3 For issues relating to digital content, see "Protecting and Empowering Consumers in the Purchase of Digital Content Products" (OECD, 2011 $\left.1_{[169]}\right)$.

4 In this context, Micklitz et. al. $\left(2017_{[170]}\right)$ have suggested that some consumer agencies may be able to use software to screen for potential unfair terms and conditions online. They have developed "uTerms" to demonstrate how such software could work in practice (uTerms, 2017 ${ }_{[171]}$ ). 